Illinois State University

ISU ReD: Research and eData

Theses and Dissertations

$4-1-2020$

\title{
The Dark Triad Predicted by Belief in Determinism and Objectification
}

Rachel Boros

Illinois State University, rrboros@aol.com

Follow this and additional works at: https://ir.library.illinoisstate.edu/etd

Part of the Clinical Psychology Commons, and the Personality and Social Contexts Commons

\section{Recommended Citation}

Boros, Rachel, "The Dark Triad Predicted by Belief in Determinism and Objectification" (2020). Theses and Dissertations. 1239.

https://ir.library.illinoisstate.edu/etd/1239

This Thesis is brought to you for free and open access by ISU ReD: Research and eData. It has been accepted for inclusion in Theses and Dissertations by an authorized administrator of ISU ReD: Research and eData. For more information, please contact ISUReD@ilstu.edu. 


\section{THE DARK TRIAD PREDICTED BY BELIEF IN DETERMINISM AND \\ OBJECTIFICATION}

\section{RACHEL BOROS}

70 Pages

While philosophers and psychologists continue to debate the existence of free will without reaching any consensus, recent attention has shifted to the matter of the consequences of belief in free will, or belief in the alternative, determinism. Proponents of the latter position argue that human behavior is the result of causal forces, which implies a lack of autonomy in decision-making and inevitability (Paulhus \& Carey, 2011). Recent research has found consequences of belief in determinism that include the promotion of undesirable behavior and undermining of moral behavior (Vohs \& Schooler, 2008), impulsive and selfish responses demonstrated through aggression (Baumeister, Masicampo, \& DeWall, 2009), and a diminished ability to learn from negative emotions (Stillman \& Baumeister, 2010). Belief in determinism may be a belief that allows some to abrogate moral responsibility, which may facilitate other antisocial tendencies. Objectification (i.e., seeing and ultimately treating a person as an object in a manner that dismisses that persons' humanity) may be one such tendency. To my knowledge, no research has examined the association between belief in determinism, interpersonal objectification, and the Dark Triad (Paulhus \& Williams, 2002). In the present research, four questionnaires measured participants' belief in free will, determinism, propensity to objectify others, narcissism, psychopathy, and Machiavellianism. Results indicated a statistically significant link between belief in determinism, interpersonal objectification, and the Dark Triad 
personality traits. A general mediation model demonstrated that interpersonal objectification mediated the relation between belief in determinism and the Dark Triad personality traits. These findings suggest that maladaptive ideologies and maladaptive personality traits share a common theme of objectifying others. Implications, limitations, and future directions are discussed. KEYWORDS: dark personality; determinism; moral responsibility; objectification 


\title{
THE DARK TRIAD PREDICTED BY BELIEF IN DETERMINISM AND OBJECTIFICATION
}

\author{
RACHEL BOROS
}

\author{
A Thesis Submitted in Partial \\ Fulfillment of the Requirements \\ for the Degree of \\ MASTER OF SCIENCE \\ Department of Psychology \\ ILLINOIS STATE UNIVERSITY
}


(C)2020 Rachel Boros 


\title{
THE DARK TRIAD PREDICTED BY BELIEF IN DETERMINISM AND OBJECTIFICATION
}

\author{
RACHEL BOROS
}

COMMITTEE MEMBERS:

Raymond M. Bergner, Chair

Daniel G. Lannin 


\section{ACKNOWLEDGMENTS}

I would like to acknowledge everyone who has supported me throughout my academic achievements. First, I am grateful for my family. I would like to acknowledge my parents who have shared their moral, financial, and physical support. I would also like to thank my friends and partner who have directly and indirectly supported me throughout the completion of my Master's.

Secondly, I would like to respectfully extend my sincere gratitude to Dr. Raymond Bergner and Dr. Daniel Lannin for their expertise, assistance, guidance, and patience throughout the process of completing this thesis. Without your help this would not have been possible. Finally, I am grateful for Illinois State University's Department of Psychology. I would like to thank the faculty members within the Clinical-Counseling Psychology Master's Program and my colleagues for their continuous assistance and encouragement. Thank you all for your unwavering support.

R.B. 


\section{CONTENTS}

Page

ACKNOWLEDGMENTS

TABLES

FIGURES

CHAPTER I: INTRODUCTION 1

CHAPTER II: REVIEW OF THE LITERATURE

Belief in Free Will

Free Will and Determinism Scale $\quad 4$

FAD-Plus: Free Will and Determinism 4

Free Will Inventory $\quad 6$

Effects of Belief in Free Will vs. Determinism 7

$\begin{array}{ll}\text { Objectification } & 11\end{array}$

Nussbaum's Conceptualization 11

$\begin{array}{ll}\text { The Dark Triad } & 16\end{array}$

$\begin{array}{ll}\text { Narcissism } & 17\end{array}$

$\begin{array}{ll}\text { Psychopathy } & 20\end{array}$

$\begin{array}{ll}\text { Machiavellianism } & 21\end{array}$

$\begin{array}{ll}\text { The Present Study } & 22\end{array}$

$\begin{array}{ll}\text { Hypotheses } & 23\end{array}$

$\begin{array}{ll}\text { CHAPTER III: METHOD } & 26\end{array}$

$\begin{array}{ll}\text { Participants } & 26\end{array}$

$\begin{array}{ll}\text { Instruments } & 26\end{array}$ 
$\begin{array}{ll}\text { Free Will } & 26\end{array}$

$\begin{array}{ll}\text { Interpersonal Objectification } & 27\end{array}$

$\begin{array}{ll}\text { Dark Triad } & 29\end{array}$

$\begin{array}{lr}\text { Objectification } & 29\end{array}$

$\begin{array}{ll}\text { Procedure } & 30\end{array}$

$\begin{array}{ll}\text { Data Analysis Plan } & 30\end{array}$

CHAPTER IV: RESULTS

Main Analyses $\quad 33$

$\begin{array}{ll}\text { Narcissism } & 36\end{array}$

$\begin{array}{ll}\text { Psychopathy } & 37\end{array}$

$\begin{array}{ll}\text { Machiavellianism } & 38\end{array}$

CHAPTER V: DISCUSSION

$\begin{array}{ll}\text { Implications } & 42\end{array}$

Limitations and Future Directions $\quad 45$

$\begin{array}{ll}\text { Conclusion } & 46\end{array}$

$\begin{array}{ll}\text { REFERENCES } & 47\end{array}$

APPENDIX A: FREE WILL INVENTORY

APPENDIX B: INTERPERSONAL OBJECTIFICATION SCALE VALIDATION 58

APPENDIX C: INTERPERSONAL OBJECTIFICATION SCALE $\quad 61$

APPENDIX D: SHORT DARK TRIAD

APPENDIX E: OBJECTIFICATION SCALE

APPENDIX F: INFORMED CONSENT 66

APPENDIX G: DEBRIEFING STATEMENT $\quad 69$ 


\section{TABLES}

Table

Page

1. Means and Standard Deviations for Belief in Free Will, Interpersonal Objectification, and The Dark Triad Measures

2. Correlations among Scores on Belief in Free Will, Interpersonal Objectification, and The Dark Triad Measures 


\section{FIGURES}

Figure $\quad$ Page

1. Hypothesized mediation model. 25

2. Unstandardized regression coefficients for the mediation analysis of belief in determinism, interpersonal objectification, and narcissism.

3. Unstandardized regression coefficients for the mediation analysis of belief in determinism, interpersonal objectification, and psychopathy.

4. Unstandardized regression coefficients for the mediation analysis of belief in determinism, interpersonal objectification, and Machiavellianism. 


\section{CHAPTER I: INTRODUCTION}

The issue of whether free will exists has been a religious and philosophical debate for centuries. Belief or disbelief in free will is now considered more than philosophical opinion or religious ideology. Of late, attention has shifted to understanding how belief or disbelief in free will may operate within society and influence social interactions (e.g., Baumeister \& Brewer, 2012; Bergner \& Ramon, 2013; Carey \& Paulhus, 2013; Moynihan, Igou, \& van Tilburg, 2017; Vohs and Schooler, 2008; Zhao, Liu, Zhang, Shi, \& Huang, 2014). An individual's philosophical beliefs, such as disbelief or belief in free will, have the potential to cause distinct patterns of overt behavior (Carmody \& Gordon, 2014). Studying the behavioral consequences of disbelief in free will is particularly important because of the negative outcomes associated (Caspar, Vuillaume, Magalhães De Saldanha da Gama, \& Cleeremans, 2017). Disbelief in free will was found to predict devious, egocentric, aggressive, and conforming behavior, to thwart helpfulness, diminish learning from adverse emotions, and increase prejudice and judgment (Baumeister \& Brewer, 2012; Genschow, Rigoni, \& Brass, 2017).

The correlates and effects of belief in free will have been studied through measurement (Nadelhoffer, Shepard, Nahmias, Sripada, \& Ross, 2014; Paulhus \& Carey, 2011; Rakos, Laurene, Skala, \& Slane, 2008) and experimental manipulation (Alquist, Ainsworth, \& Baumeister, 2013; Baumeister, Masicampo, \& DeWall, 2009; Vohs \& Schooler, 2008). Results have demonstrated an association between belief in determinism and antisocial and aggressive behavior (Baumeister, Masicampo, DeWall, 2009), diminished prosocial behavior (Stillman \& Baumeister, 2010), and a reduced sense of moral responsibility (Shariff, Greene, Karremans, Luguri, Clark, Schooler, Baumeister, \& Vohs, 2014). 
The purpose of the present study is to further examine potential implications of believing in free will; more specifically, if and how a belief in the alternative, determinism, may affect individuals' behavior and psychological wellbeing. It is my intention to expand upon existing research, research that currently supports the position that belief in determinism may lead individuals to identify less with the notion of moral responsibility. Relatedly, I am interested in determining if there is a relationship between belief in determinism and four other variables: (1) an individual's tendency to objectify others; (2) the presence of narcissism; (3) the presence of some degree of psychopathy; and (4) the presence of some degree of Machiavellianism (collectively, the latter three have been termed "the Dark Triad"'Paulhus \& Williams, 2002]). 


\section{CHAPTER II: REVIEW OF THE LITERATURE}

\section{Belief in Free Will}

Belief in free will can be conceptualized as involving an individual's sense of agency and responsibility. The belief in free will can be further described as an individual's belief in their ability to sustain autonomy in their behavior, which includes belief in morality and an internal locus of control (Paulhus \& Carey, 2011). Belief in free will encourages individuals to consider multiple possibilities, provided there are alternatives and more desirable actions, and ultimately take responsibility for their chosen actions (Baumeister \& Brewer, 2012). Such a belief holds that decisions are made by genuine choices of individuals who, given behavioral alternatives of which they are aware, choose from and perform one of these (Bergner \& Ramon, 2013).

As laypersons define it, belief in free will is the belief that one has the ability to make choices that are in line with their thoughts, feelings, and desires, that are unconstrained by external factors, contingent upon planning and forethought (Feldman, Baumeister, \& Wong, 2014). Philosophical theory argues that belief in free will is a necessary prerequisite for moral responsibility. Recent literature has supported the notion that laypersons associate the belief in free will with moral choice and one's ability to learn, mature, and behave differently (Feldman, Wong, \& Baumeister, 2016).

Recent skepticism has questioned the validity of beliefs in free will, and instead supported the alternative position known as "determinism." Belief in determinism is essentially antithetical to a belief in free will. Philosophers typically define determinism as a philosophical position that argues that, as things are now in the present, there is only one possibility for the future. Determinism holds that there are no alternatives, instead there is only one possible future (Müller \& Placek, 2018). According to scientists, determinism is not a proven fact; rather it is a 
crucial assumption. It is an assumption that claims that human thoughts and actions are determined in advance and are subject to deterministic causality; essentially arguing that human behavior is the result of causal forces set in motion at the time of the origin of a behavior (Baumeister et al., 2009). For example, one recent, neuroscientifically-based version of determinism argues that human behavior involves the firing of neurons that cause thoughts and eventually actions. These firings can then be connected in a causal chain back to birth, therefore arguing that individuals are not actually in control of their behavior (Cave, 2016). This belief places the responsibility for decision-making on external forces.

Considering the complex nature of the concept and the consequences associated with these beliefs, psychologists have utilized multidimensional scales to understand these beliefs. To further understand the current conceptualization of belief in free will and determinism, I explored the established scales used to measure these philosophical positions.

\section{Free Will and Determinism Scale}

The Free Will-Determinism Scale (Viney, Waldman, \& Barchilon, 1982) was originally developed to understand the philosophy of punishment and beliefs in free will and determinism. In this scale, Viney et al. (1982) defined free will as, "the doctrine that assumes that we make real choices which are partially or completely independent of antecedent conditions.

Determinism denies this and maintains that causation is operative in all human affairs. Thus, socalled choices are influenced or determined by antecedent conditions” (p. 946).

\section{FAD-Plus: Free Will and Determinism}

Based on the preliminary, unpublished version (FAD-4; Paulhus \& Margesson, 1994), Paulhus and Carey (2011) developed a measure of lay beliefs in free will and associated constructs. The 27-item FAD-Plus includes four subscales: Free Will, Scientific Determinism, 
Fatalistic determinism, and Unpredictability. This measure included key constructs, refrained from the use of philosophical jargon, avoided incompatibilist assumptions, and increased relative independence of subscales.

Paulhus and Carey (2011) distinguished between two distinct types of determinism: scientific and fatalistic. Scientific determinism places an emphasis on "scientific causality" (p. 102), in turn, scientific determinism relies on both an internal and external locus of control. This position allows for decision-making, recognizing that not everything is predetermined. Fatalistic determinism argues for causal explanations of inevitability and lack of autonomy in decisionmaking. At the extreme, fatalistic determinism places behavioral control strictly on inevitable external forces and maintains that something is going to happen no matter what. Unpredictability argues that free will exists as a result of scientists inability to predict human behavior without fault, and conversely, not believing in determinism is not obligatory for believing in free will (Paulhus \& Carey, 2011).

While previous measures of belief in free will maintained incompatibilist assumptions (i.e., belief in free will and determinism are mutually exclusive positions), Paulhus and Carey (2011) found that free will and determinism are compatible. Explained in a later study, Carey and Paulhus (2013) argue that individuals typically believe in free will and determinism, and a disbelief in one does not require the belief in the other. Research suggests that a majority of individuals believe in free will, "at least to some extent" (Carey \& Paulhus, 2013, p. 138), while at the same time, individuals understand that some decisions are externally influenced (Baumeister, 2008).

Within this measure, Paulhus and Carey (2011) unwittingly captured the concept of locus of control explained by Rotter (1966). Acknowledging the similarity of the concepts, Paulhus 
and Carey (2011) intentionally distinguished between free will and determinism, and internal and external locus of control. Conceptually, free will beliefs are compatible with an internal locus of control with the inclusion of moral responsibility. Scientific determinism includes both an internal and external locus of control. Conversely, fatalistic determinism assumes inevitability of external forces. While these constructs closely resemble the notion of locus of control, the FADPlus does not directly coincide with internal and external locus of control. Surprisingly, authors explained a modest relation between unpredictability and fatalistic determinism, potentially because fate and unpredictability are external forces and remain unknowable (Paulhus \& Carey, 2011).

\section{Free Will Inventory}

Previous results have been difficult to interpret, and the psychometric tools used to measure these beliefs have been arguably problematic. On that account, Nadelhoffer and colleagues (2014) recognized the importance of considering the researchers conceptualization of free will and how this may influence their experiments, line of questioning, and interpretation of results. For those reasons, Nadelhoffer et al. (2014) developed a self-report measure to address the limitations of the previously established measures (e.g., theory contamination, incompatibilist assumption, limited diversity in sampling). The Free Will Inventory (FWI) avoids the use of incompatibilist assumptions and, instead captures a broader range of beliefs and attitudes. The final scale included two parts; part 1 included fifteen items that successfully measures independent constructs of free will, determinism, and dualism/anti-reductionism. Part 2 includes fourteen statements that measure the strength and relationship of beliefs in free will, determinism, and dualism. 


\section{Effects of Belief in Free Will vs. Determinism}

Vohs and Schooler (2008) conducted a study that assessed participants' likelihood to cheat after being exposed to a message prompting them to believe that all human behavior is essentially predetermined. Results demonstrated that subjection to a message claiming that free will does not exist can increase passive and active cheating. These findings suggest that disbelief in free will had the potential to promote undesirable behavior and undermine moral behavior. Using an adapted version of Vohs and Schooler's (2008) free will belief manipulation, Baumeister, Masicampo, and DeWall (2009) conducted several experiments looking to investigate disbelief in free will as it pertains to self-control and the likelihood to exert helpfulness or aggression. Results suggested that, independent of mood and emotion, disbelief in free will leads to impulsive and selfish responses, demonstrated through aggression and refusal to help.

Stillman and Baumeister (2010) later argued that belief in free will serves as an influential factor in learning from emotions and that disbelief in free will might sabotage learning from emotional experiences. Within the study, participants were asked to consider past actions that they felt guilty about and communicate any lessons they may have taken away from them. Those who believed more strongly in free will, and identified themselves as feeling guilty, derived more valuable lessons than those who believed in free will to a lesser extent, if at all. These results suggested that belief in determinism diminished individuals' learning from emotional experiences.

In a later study, Carey and Paulhus (2013) investigated political orientation, moral attitudes, and punitiveness as they relate to belief in free will. In their study, participants were asked to read a vignette depicting a child molester and later recommended a sufficient prison 
sentence for the offender. Participants were then presented with further information explaining that the molester had been abused as a child and suffered from psychopathology. After introducing these details, participants were able to revise their original recommended prison sentence. Results of this study showed that participants with a greater belief in free will were more likely to recommend a longer prison sentence; conversely, a belief in scientific determinism or fatalism had no effect. This research suggests a link between belief in free will, conservative social attitudes, obligatory moral foundations, and retributive punishment of theoretical criminals. That is to say, an individual capable of exerting more self-control is more likely to be highly conscientious and supportive of a conservative worldview that upholds moral foundations (Carey \& Paulhus, 2013).

Bergner and Ramon (2013) argued that the notion of reduced responsibility is associated with alterations in the individual's actual behavior and with the belief that, if one has no choice in the matter, there is no morality to be considered. Bergner and Ramon (2013) investigated the association between beliefs in altruism, free will, and nonreductionism (i.e., the view that argues that thoughts, beliefs, and motives cannot be reduced to just the brain and physiological processes) in comparison with the opposing beliefs in psychological egoism, determinism, and biological reductionism. Results of their study demonstrated that altruism, belief in free will, and nonreductionism were strongly correlated with "a heightened sense of meaning in life, higher levels of life satisfaction, a belief in morality as a legitimate and important dimension in life, and higher standards of personal moral conduct" (Bergner \& Ramon, 2013, p. 610). This furthers the argument that belief in free will is valuable and adaptive to human society through the support of prosocial behavior and reduction of antisocial behavior. 
Recognizing that belief in free will implies the absence of external factors outside of one's own thoughts, values, and choices, Alquist, Ainsworth, and Baumeister (2013) argued that belief in free will reduces conformity. Using several studies, these authors found that a diminished belief in free will resulted in an increased likelihood to conform to others' opinions regardless of mood and emotion. Therefore, Alquist et al. (2013) posited that belief in free will encourages individuals to act on their own volition and think for themselves, whereas reduced belief in free will is associated with low volitional effort and self-control.

Feldman, Wong, and Baumeister (2016) later extended the concept of belief in free will beyond morality and punishment, to consider accountability; arguing that, the notion of accountability in this sense is referring to the "acknowledgement and assumption of responsibility. Thus, if a behavior or an outcome deviates from the expected, then an accountable person accepts their own role and seeks to learn from mistakes and correct future actions" ( $p$. 27). In this sense, a judgment based on accountability is ultimately a decision that an individual could have acted differently, implying that they could have done so in the first place. This assertion supports the conception that most laypersons have regarding the belief in free will; that is to say, that an individual has the ability to make a choice in whether to act differently in the same situation (Feldman et al., 2016). A lack of felt responsibility or accountability may lead individuals to detach themselves from the decision-making process with the belief that weighing moral and ethical consequences of behavior makes no difference. As a result, individuals who hold deterministic views may stop seeing themselves as accountable for their actions and ultimately void of blameworthiness; as such, they may be more willing to give into their impulses and act less responsibly (Cave, 2016). 
In research relevant to mental health issues, disbelief in free will has been associated with addiction and has been studied with regard to behavioral control in psychopaths. The large majority of health professionals, and consequently the public, understands addiction as a disease that is caused by an interaction between an individual's brain and foreign substances, classified as addictive drugs. However, there has been an increase in literature regarding a controversial view, that addiction is more or less a disorder of choice (Glannon, 2011). For this reason, Vonasch and colleagues (2017) conducted a study to examine the relationship between belief in free will and addiction. Results demonstrated that individuals with lower belief in free will were more likely to have a history of alcohol or drug addiction, and that addiction can be understood as a loss of free will. Interestingly, this study found that belief in free will as it relates to addiction can work in both directions, that inducing disbelief in free will led individuals to see more addiction in the world, and that reading arguments opposing the belief in free will led individuals to ridicule their own self-control. These authors concluded that, "while people associate becoming addicted with loss of free will, they associate quitting addiction with increased free will” (Vonasch, Clark, Lau, Vohs, \& Baumeister, 2017, p. 65).

Overall, previous research on the effects of belief in free will seems to suggest that both personal and societal gain lie in believing and acting in ways that support persons believing in autonomy of choice and free will. The individual is left with a sense of responsibility for their choices and the repercussions of the behavioral alternative chosen. Holding this view, individuals may be more mindful in their decision-making process, allocating more attention to their decisions, rather than acting impulsively. 


\section{Objectification}

First introduced by Immanuel Kant, the word objectification is most commonly used in a derogatory manner to describe the treatment of individuals solely as a means to an end; treating an individual as an object that is evaluated based on what the objectified can do for the objectifier. Objectification is seeing and ultimately treating a person as an object in a manner that dismisses that person's humanity. For Kant, objectification involved the harming of an individual's humanity, which is an individual's capacity for rational choice and nature. Humanity allows humans to determine what is valuable and take steps to promote that value. Therefore, Kant stresses, "humanity is never treated merely as a means, but always as an end in itself" (Papadaki, 2010, p. 18). Objectification is considered a medium for subjugation by which an objectifier disregards or diminishes the needs and interests of the target. The process of objectification involves, "instrumental fragmentation in social perception, the splitting of a whole person into parts that serve specific goals and functions for the observer" (Gruenfeld, Inesi, Magee, \& Galinsky, 2008, p. 111).

Freud argued that objectification was essentially infantile narcissism at a young age, and that objectification is considered developmentally appropriate and even necessary, as a means for survival at a young age. However, when the self-centeredness and objectification continue into adulthood, as it does to some degree for everyone, it can become problematic and, in some cases, may develop into narcissistic personality disorder (Fast, 1985).

\section{Nussbaum's Conceptualization}

American Philosopher Martha Nussbaum, known for her literary works on objectification, explained objectification using seven dimensions. In Nussbaum's paper, "Objectification" (1995), she introduced the seven nonhierarchical classifications of 
instrumentality, denial of autonomy, inertness, fungibility, violability, ownership, and denial of subjectivity as ways in which possessions are treated. Nussbaum defined these as:

1. Instrumentality: The objectifier treats the object as a tool for his or her purposes

2. Denial of autonomy: The objectifier treats the object as lacking in autonomy and selfdetermination.

3. Inertness: The objectifier treats the object as lacking in agency, and perhaps also in activity.

4. Fungibility: The objectifier treats the object as interchangeable (a) with other objects of the same type, and/or (b) with objects of other types.

5. Violability: The objectifier treats the object as lacking in boundary-integrity; as something that is permissible to break up, smash, or break into.

6. Ownership: The objectifier treats the object as something that is owned by another, can be bought or sold, etc.

7. Denial of subjectivity: The objectifier treats the object as something whose experience and feelings (if any) need not be taken into account (Nussbaum, 1995, p. 257).

Emphasized in this description is the idea that objectification is the "making into a thing, treating as a thing, something that is not really a thing," and the process of objectification is the treatment of human beings in one or more of these ways (Nussbaum, 1995, p. 257). From the seven prototypical features, Nussbaum determined that denial of autonomy and instrumentality are the necessary features of objectification. Autonomy is an important function of moral equality; therefore, the denial of an individual's autonomy is the denial of his or her personhood. Once autonomy is revoked, the objectified individual is degraded, violated, and subject to replacement, like that of an object (Cahill, 2011). Cahill (2011) notes that instrumentality has the 
potential to result in denial of autonomy, "when it does so, it becomes morally problematic; and indeed, given the close conceptual relationship between instrumentality and lack of autonomy, the former almost always entails the latter" (p. 15).

When used in psychological research, objectification considers what is emphasized (i.e., the body), whereas objectification, in the philosophical sense, emphasizes what is denied (i.e., humanity) (Loughnan, Haslam, Murnane, Vaes, Reynolds, \& Suitner, 2010). Loughnan and colleagues (2010) found that objectification influenced depersonalization, regardless of gender. More specifically, " as objectification increased, mind attribution decreased, and moral status was withdrawn" (p.716).

Orehek and Weaverling (2017) argued that, in terms of psychological principles, objectification requires the perception and evaluation of targets based on their instrumentality to an actor's goal. Instrumentality is then established through the means-goal mental relationship, which is reinforced when the goal is successfully achieved (Orehek \& Weaverling, 2017). The goal system theory (Shah, Kruglanski, \& Friedman, 2003) posits that goals are associated with their means of achievement through their instrumental associations. This instrumentality is determined through knowledge that the means will lead to the achievement of the particular goal. Perceived instrumentality mediates the relationship between means-goal association and goal performance, with high perceived instrumentality leading to greater execution in goal pursuit (Zhang \& Tu, 2011). If a strong association between the attainment-means and the goal exists, individuals will perceive more instrumentality in goal achievement and the goal will be pursued at the others expense (Rector, 2017).

From this psychological perspective, instrumental attraction leads to instrumental behavior and approach toward the objectified target with an emphasis on a target's usefulness in 
achieving the actor's goal (Gruenfeld et al., 2008). Gruenfeld and colleagues (2008) argued that goals can affect how targets are evaluated in ongoing relationships and influence the evaluation and choice of new relationship partners, regardless of their human qualities. In six studies, these authors found that individuals with greater power were more attracted to a target's usefulness with respect to the observers' goals, in comparison to those with lower power. Using an objectification scale associated with power and work relationships, Gruenfeld et al. (2008) found that individuals reported greater objectification in relationships with subordinates than peers, and individuals high in power generally reported a higher level of objectification in relationships with peers.

Rector (2017) argued that objectification, while potentially problematic, is not always dehumanizing. Instead, it can be viewed as a continuum that includes causal indifference, derivatization, and dehumanization. These categories may differ; however, their underlying perceptual mechanism is the same, the targets are seen as objects that aid in goal achievement. Within this continuum it is recognized that objectification, at a certain level (i.e., causal indifference), is inevitable to human beings and that it can be adaptive and advantageous to the individual. Causal indifference denotes a tendency to deny and suppress others' suffering, because objectification includes viewing others as lacking subjectivity and feelings, it can be beneficial to the objectifier to remain unaffected or unmoved by the feelings and emotions of others. At this end of the spectrum, there is no purposeful intent to be cruel or inflict harm onto others; instead, causal indifference is the demonstration of inaction (Rector, 2017).

To explain more purposeful objectification, Cahill (2011) proposes the use of the term "derivatization." She stated that, 
"If 'objectify' means 'to turn into an object,' then 'derivatize' means 'to turn into a derivative...to derivatize is to portray, render, understand, or approach a being solely or primarily as the reflection, projection, or expression of another being's identity, desires, fears, etc. The derivatized subject becomes reducible in all relevant ways to the derivatizing subject's existence — other elements of [their] being or subjectivity are disregarded, ignored or under-valued"' (p. 32).

The target of objectification is stripped of their autonomy and subjectivity as a method for use in goal pursuit. Further defined by Rector (2017), derivatization is a process of misapprehending other human beings, and one's awareness of their complexity is confused by their own self-boundary, interests, desires, and fears, and others are treated accordingly. This makes up a large portion of the continuum toward more dehumanizing classification. The less severe form of derivatization includes a blatant lack of respect for others without exercising violence, whereas more severe derivatization may involve violent abuse and exploitation. The most extreme form of derivatization is "emotional hardening," where the objectifier is entirely insensitive and unsympathetic to the target's suffering, consequently disregarding their basic human rights. However, in this sense, the objectified individual has not yet been completely dehumanized (Rector, 2017).

Dehumanization, considered to be on the extreme end of the objectification continuum, occurs when the objectifier sees others as less than human beings and more as objects. Dehumanization involves the assumption that an individual is not human, which then requires the affirmation that the individual is less than human (Rector, 2017). Causal indifference is considered to be adaptive, whereas dehumanization is not. Instead, dehumanization is an unconscious strategy for dealing with incompatible psychological motives (Smith, 2011). The 
dehumanizer's intent is to rid the individual of their humanity and transform them into nonhumans, without violence. This change occurs mentally and is a matter of perception. Once the dehumanizer has an altered view of the target, abusive behavior may follow (Rector, 2017).

Philosophers and psychologists agree that objectifiers stress the importance of the targets' instrumental utility and diminish their personhood. Objectification can be seen in sexual and nonsexual contexts, in which the person being objectified lacks warmth, competence, moral standing, and humanity. The objectified individual lacks two core elements of social perception, warmth and competence. As a result, the objectified is viewed as relatively immoral and amoral, which develops into dehumanization. Heflick and colleagues (2010) argued that the necessary human traits, characteristics of the human mind, and the stereotype content model hold that warmth, competence, and morality are the necessary perceptions of humanity. Loughnan et al. (2017) found that individuals who are objectified subsequently internalize objectification and see themselves as less warm, competent, and human. Interestingly, both men and women are equally likely to explicitly or cognitively objectify others, and influence the target, regardless of the gender of the objectifier (Loughnan, Baldissarri, Spaccatini, \& Elder, 2017).

\section{The Dark Triad}

Developed by Paulhus and Williams (2002), the Dark Triad refers to three prominent non-pathological personality traits: subclinical narcissism, subclinical psychopathy, and Machiavellianism. Despite having distinct features, there exists significant overlap among the Dark Triad traits, "[as] all three entail a socially malevolent character with behavior tendencies toward self-promotion, emotional coldness, duplicity, and aggressiveness" (Paulhus \& Williams, 2002, p. 557). These related, yet theoretically distinct personality traits are characterized by varying degrees of grandiosity, callousness, deceit, and aggression (Kowalski, Kwiatkowska, 
Kwiatkowska, Ponikiewska, Rogoza, \& Schermer, 2018). These three traits are often considered to share a significant overlap that complicates distinction; however, when studied together the distinctions is possible (Jones \& Paulhus, 2014).

\section{Narcissism}

According to the Diagnostic and Statistical Manual of Mental Disorders $\left(5^{\text {th }}\right.$ ed.; DSM-5; American Psychiatric Association, 2013), "narcissistic personality disorder is a pervasive pattern of grandiosity, need for admiration, and lack of empathy that begins by early adulthood and is present in a variety of contexts" (p. 670). Individuals diagnosed with narcissistic personality disorder typically have an inflated sense of self-importance, believe they are superior, display a sense of entitlement that may result in the conscious or unintentional exploitation of others, and often have difficulties recognizing the desires, subjective experiences, and feelings of others. Interestingly, "many successful individuals display personality traits that might be considered narcissistic. Only when these traits are inflexible, maladaptive, and persisting and cause significant functional impairment or subjective distress do they constitute narcissistic personality disorder" (American Psychological Association, 2013, p. 671). While narcissistic personality disorder is rarely diagnosed, narcissistic traits of vanity, arrogance, and lack of empathy are quite common (MacDonald, 2014).

Krizan and Herlache (2018) introduced the narcissism spectrum model as a means of conceptualizing narcissistic personality disorder, allowing the integration of personality structural and developmental framework and existing theories of narcissism. The narcissism spectrum model assumes that narcissistic features result from developmental processes that include person-situation transactions. While extreme narcissism is deemed maladaptive and 
therefore classified as a personality disorder, a certain degree of narcissism is needed for healthy self-esteem (Krizan \& Herlache, 2018).

Narcissism refers to the ability to manage self-esteem, needs for affirmation, validation, and self-enhancement within the social environment. To laypersons, narcissism is frequently associated with arrogance, conceitedness, and authoritarian attitudes and behaviors. Theorists suggest that narcissism has adaptive and maladaptive expressions that reflect adaptive and maladaptive personality characteristics and psychological needs, which influences one's need for self-enhancement and validation (Pincus \& Lukowitsky, 2010).

The trait approach to non-pathological narcissism, proposed by Raskin and Hall (1979), considers narcissism on continuum, which includes personality traits, beliefs, and behaviors that differ in the degree to which they are displayed or acted upon. According to MacDonald (2014), we all fall somewhere along this continuum, with narcissistic responses ranging from mild to a potentially pathological level of narcissism. The lower end of this continuum includes individuals who display narcissistic behaviors but are capable of functioning well personally and socially (Mielimaka, Ogrodniczuk, Kealy, Cheek, \& Joyce, 2018). Healthy narcissism incorporates, “a steady sense of one's worth, based on genuine achievement, the capacity to recover from disappointment or failure and the ability to find comfort and support in relationships" (MacDonald, 2014, p. 145). On the opposite end of the continuum are those who suffer from unhealthy or pathological narcissism. Individuals on this end of the continuum act in domineering, vindictive, and disruptive behaviors, leading to issues in maintaining meaningful, long-term relationships and experience difficulty in enacting prosocial behaviors due to their egocentrism, grandiosity, and poor self-awareness (Mielimaka et al., 2018). Although rare, extremely unhealthy narcissism can be classified as narcissistic personality disorder. 
Narcissism can be categorized into two variants: grandiose and vulnerable. Grandiosity is considered a defense against feelings of inferiority that is typically described as, "an inflated positive self-image, high self-esteem, exhibitionism, attitudes of entitlement, a tendency toward exploitativeness, self-assuredness, aggression, and the need to be admired by others" (Zajenkowski, Witowska, Maciantowicz, \& Malesza, 2016, p. 102). Grandiose narcissism is positively associated with high levels of extraversion, emotional stability, and conscientiousness, while negatively correlated with cooperation and morality (Persson, 2019). A study conducted by Zajenkowski et al. (2016) demonstrated that narcissism, specifically grandiose narcissism, is associated with hedonism, which in turn corresponds to a constant striving toward possession, immediate reward, an illusion of control, and overconfidence that allows for the dismissal of potential consequences to behavior.

In contrast, individuals exhibiting vulnerable narcissism are described as needing recognition from others that is indicative of their sense of self-worth. This need for admiration and validation is directly linked to a vulnerable narcissist's characteristically low sense of selfworth, emotional instability, hostility, insecurity, anxiety, and defensiveness (Malesza \& Kaczmarek, 2018). Vulnerable narcissism is negatively correlated with self-efficacy, openness to experience, and various facets of agreeableness (i.e., trust, morality, altruism). Grandiose and vulnerable narcissism are separate constructs; however, research suggests that narcissistic individuals will fluctuate between grandiose and vulnerable states, and that grandiosity may actually serve as a defense against vulnerability (Wright, Stepp, Scott, Hallquist, Beeney, Lazarus, \& Pilkonis, 2017). Research suggests a stronger association between grandiose narcissism and impulsivity, when compared to vulnerable narcissism (Malesza \& Kaczmarek, 2018). 


\section{Psychopathy}

Antisocial personality disorder (ASPD), as it is explained in the DSM-5, involves "a pervasive pattern of disregard for and violation of the rights of others that begins in childhood or early adolescence and continues into adulthood. This pattern has also been referred to as 'psychopathy,' 'sociopathy,' and 'dissocial personality disorder'”' (American Psychological Association, 2013, p. 659). Narcissistic personality disorder and antisocial personality disorder share overlapping features such as a general lack of empathy, exploitation of others, and an exaggerated sense of self-importance (Maddux \& Winstead, 2016).

Psychopathy is considered a pattern of personality traits with stimulus seeking, social deviance, and interpersonal/affective traits as central features. According to the Hare Psychopathy Checklist-Revised (PCL-R; Hare 1991, 2003), psychopathy is categorized by four dimensions: Interpersonal (glibness, grandiose sense of self-worth, pathological lying and deception, and manipulativeness); Affective (lack of remorse or guilt, shallow affect, callousness and lack of empathy, and failure to accept responsibility); Lifestyle (stimulation seeking, parasitic lifestyle, impulsivity, irresponsibility, and lack of realistic goals); and Antisocial (poor behavioral controls, early behavior problems, juvenile delinquency, criminal versatility and revocation of conditional release). Psychopathy is also categorized by promiscuous sexual behavior and numerous short-term relationships (Hare \& Neumann, 2008).

American psychiatrist and pioneer in the field of psychopathy, Hervey Cleckley, described a psychopath as "a fully functioning person in every respect except that he cannot feel" (Cleckley, 1950, p. 398-399). The emotional deficits associated with psychopathy result in further deficits in moral motivation and moral competence. Surprisingly, these deficits do not seem to impair their social understanding and social skills, as they are capable of determining 
what are socially acceptable and morally appropriate responses to an array of situations. This ability for maintenance of social awareness enables them to disguise themselves by mimicking and acting in ways that are compatible with societal norms and considered morally just, and in turn, allowing them to appear sane (Magnani, 2012; Maxwell \& Le Sage, 2009). According to Cleckley (1984) and Hare (1999), psychopaths possess average, possibly even superior, social perspective-taking skills, which may account for the psychopathic traits of manipulativeness and deceit. In fact, "it is precisely their strong perspective-taking abilities, aided by very low concern for others, that explains why psychopaths are so adept at taking advantage of others" (Maxwell \& Le Sage, 2009, p. 80).

\section{Machiavellianism}

Christie and Geis (1970) introduced the concept of Machiavellianism to the personality literature, inspired by the publication of the book entitled The Prince, written by Italian Renaissance diplomat and political theorist Niccoló Machiavelli in 1532. Throughout this book, Machiavelli urges kings and lords to ensure their power through meticulously planned and potentially immoral deeds, promoting that the ends will justify the means (Beller \& Bosse, 2017). “Traditionally, the 'Machiavellian' is someone who views and manipulates others for [their] own purposes" (Christie \& Geis, 1970, p. 1). Individuals of this nature typically view others as objects to be manipulated, disregard conventional morality, lack overt psychopathology, and have low ideological commitment, in an effort to promote their own goals (Beller \& Bosse, 2017). Machiavellians focus on maintaining their reputation and building alliances. They are strategic regarding the tactics employed to pursue the goal, as opposed to impulsive like that of psychopaths. These individuals are frequently endowed with high inference, reasoning, and planning capabilities (Jones \& Paulhus, 2014). 
Both previously explained features of the Dark Triad, narcissism and psychopathy, are associated with clinical disorders; however, Machiavellianism is not. As such, Rauthmann and Will (2011) proposed a multidimensional model of Machiavellianism with cognitive, emotional, motivational, and behavioral themes. Machiavellians are prototypically characterized by cold affect, particularly in interpersonal situations, absence of remorse, and a strategic orientation to planning. They may utilize different schemas involving deceit, lying, and cheating, to get what they want. All come easy to them given their characteristically cynical attitudes, negative worldview, immoral beliefs and self-centeredness. Machiavellians frequently demonstrate instrumentality in pursuing materialistic goals (i.e., status, money, power), while showing little interest in collective goals (i.e., harmony and love) (Rauthmann \& Will, 2011).

\section{The Present Study}

Previous research has found that belief in free will is positively associated with an individual's sense of autonomy, accountability, and morality, as well as enhanced interpersonal relationships and a tendency to contribute positively to societal values. Whereas, the effects of not believing in free will, and alternatively believing in determinism, include dishonesty, selfishness, aggression, and conforming behavior (Baumeister \& Brewer, 2012).

The present study expanded upon current understanding that belief in determinism is related to a general disregard for societal rules and norms, and maladaptive personality traits. This finding has been well-supported in many studies, however, one of the possible effects of belief in determinism that has not yet been studied is the tendency to objectify other individuals (i.e., to essentially see them as less as co-entitled individuals and more as objects that are means to one's own personal ends). Therefore, the primary purpose of this study was to examine the effects of belief in determinism as it may relate to interpersonal objectification. More 
specifically, I investigated whether interpersonal objectification would mediate the relationship between belief in determinism and the Dark Triad personality traits of narcissism, psychopathy, and Machiavellianism. The present study conceptualized belief in free will and belief in determinism using the free will and determinism subscales from the FWI. This measure was selected for this study because of the well-established reliability and validity of the measure itself.

\section{Hypotheses}

To my knowledge, no previous research has attempted to investigate the relation between belief in determinism and interpersonal objectification; therefore, the primary aim of this study was to explore whether belief in determinism was associated with interpersonal objectification. Because previous research has demonstrated an association between belief in determinism and reduced prosocial tendencies, it was conceivable that belief in determinism may be one such belief that allows some to abrogate moral responsibility, and in turn, facilitate other antisocial tendencies. Carey and Paulhus (2013) proposed that future studies should investigate how disbelief in free will might lead individuals to be less morally critical of others, which this study aimed to accomplish.

Hypothesis $1 A$ was that higher levels of belief in determinism would be positively associated with individuals' propensity to objectify others. Hypothesis $1 B$ was that higher levels of belief in free will would be negatively associated with individuals' propensity to objectify others. More specifically, belief in determinism would be positively associated with the seeing and ultimately treating a person as an object in a manner that dismisses that person's humanity.

In a similar vein, this study investigated the association between belief in determinism and individuals' propensity to exhibit personality traits of the Dark Triad. The Dark Triad 
includes the dark personality traits of narcissism, psychopathy, and Machiavellianism, which are collectively known to share characteristics of disagreeableness, callousness, deceit, and manipulativeness. As argued in the literature, belief in determinism can promote a general disregard for moral responsibility, encourage a sense of entitlement and selfishness, and the dismissal of potential consequences of behavior. Based on this notion, I hypothesized that if an individual identified with deterministic beliefs, they might also exhibit signs of narcissism, as the two appear to be related. Thus, Hypothesis 2 predicted that belief in determinism, relative to belief in free will, would be positively associated with individuals' propensity to demonstrate narcissistic qualities.

For my third hypothesis, I expected that belief in determinism would be positively associated with individuals' propensity to be characteristically psychopathic. More specifically, Hypothesis 3 predicted that, if an individual identifies with deterministic beliefs, they may be more susceptible to psychopathy, as individuals identifying with this belief will deem the consequences of their impulsive behavior a matter of inevitability and fail to acknowledge moral responsibility, thereby disregarding for the rights and wellbeing of others.

Along with the previously cited features of the Dark Triad, narcissism and psychopathy, Machiavellianism is characterized be emotional instability and lower regard for morality. Research has shown that Machiavellianism is associated with flexible moral beliefs and emotional detachment, which allows for pragmatic decision-making in personal conflicts (Karandikar, Kapoor, Fernandes, \& Jonason, 2019). Therefore, Hypothesis 4 predicted that belief in determinism, as opposed to belief in free will, would be positively associated with higher degrees of Machiavellianism and the propensity to manipulate others. 
Finally, this study examined a potential mediation model between belief in determinism and the Dark Triad personality traits through interpersonal objectification and explored whether a mediation effect of interpersonal objectification existed between belief in determinism and dark personality traits. Hypothesis 5 was that interpersonal objectification would explain the relationship between belief in determinism and the Dark Triad (Machiavellianism, narcissism, and psychopathy). Specifically, I predicted that objectification (i.e., seeing and treating others as means to one's own end) would explain the relationship between belief in determinism and the manifestation of dark personality traits (see Figure 1).

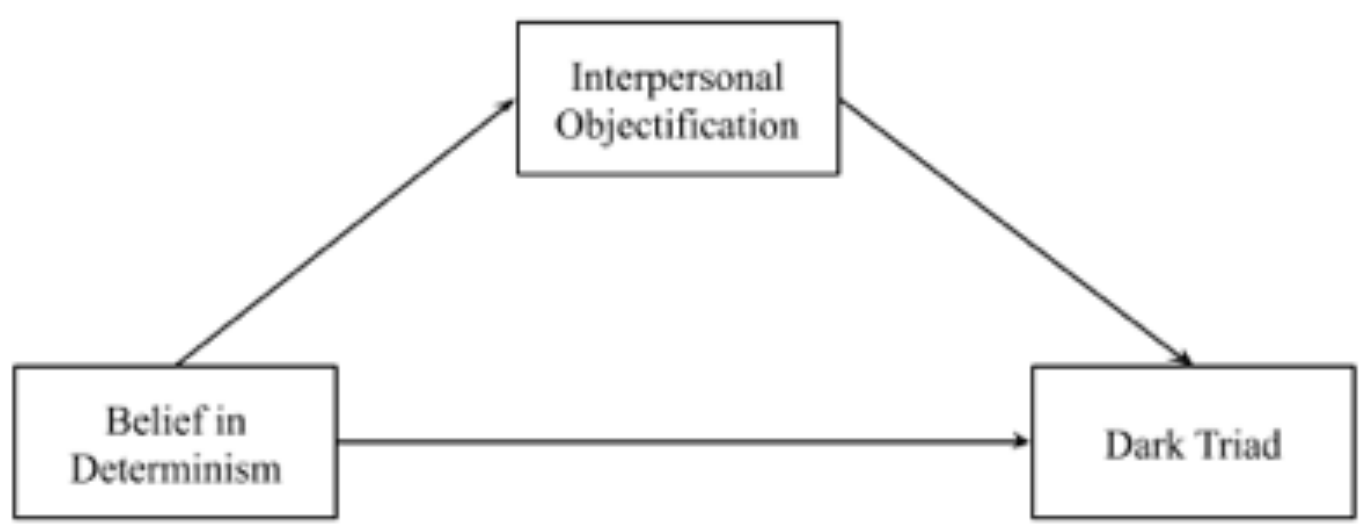

Figure 1. Hypothesized mediation model. 


\section{CHAPTER III: METHOD}

\section{Participants}

Participants were students attending Illinois State University. A total of 608 students participated in this study (117 men, 431 women, 3 transgender men, 2 transgender women, 6 non-binary individuals, and 1 non-binary woman; 48 individuals did not to respond). The participants' ages ranged from 18 to $55(M=21.34, S D=4.37)$. The majority of students identified as White/Caucasian (75.0\%), whereas 6.1\% identified as Hispanic/Latinx, 4.8\% identified as Black/African American, and 3.8\% identified as Asian American. The remainder of the students identified as Biracial/Mixed (0.9\%), Native American (0.3\%), Pacific Islander $(0.2 \%), 1.2 \%$ of the participants chose "prefer not to answer," and $7.7 \%$ of the participants did not answer.

\section{Instruments}

\section{Free Will}

The Free Will Inventory (FWI) measures belief in free will, while simultaneously measuring an individual's belief in determinism, dualism, and non-reductionism (Nadelhoffer, Shepard, Nahmias, Sripada, \& Ross, 2014). This 29-item self-report inventory consists of two parts, both using a 7-point Likert-type scale ranging from strongly disagree to strongly agree. Part 1 consists of three 5-item subscales that assess the strength of belief in free will, determinism, and dualism, respectively. Part 2 of the FWI is made up of 14 statements that consider the relationship between these beliefs. These additional statements allow for further exploration of individuals' corresponding beliefs and attitudes about free will, determinism, choice, the soul, predictability, responsibility, and punishment. For the purposes of this study, only the free will and determinism subscales were used. The free will subscale included items 
such as, "people always have the ability to do otherwise," and the determinism scale included items such as, "everything that has ever happened had to happen precisely as it did, given what happened before" (see Appendix A). For this study, the Free Will and Determinism subscales achieved coefficient alphas of .81 and .76 respectively.

\section{Interpersonal Objectification}

Due to the lack of an existing measure of interpersonal objectification (vs. selfobjectification) in the literature, the Interpersonal Objectification (IO) scale was created for the purposes of this study. This measure was developed based on philosopher Martha Nussbaum's conceptual analysis of objectification using the seven features (instrumentality, denial of autonomy, inertness, fungibility, violability, ownership, and denial of subjectivity) that she employed to describe the phenomenon of one person treating another as an object (i.e., objectifying them); A pool of 79-items were generated to map onto these seven features. Ten expert raters (i.e., psychology graduate students) were asked to validate this measure by rating each item's relevance to objectification, using a multiple-choice format (i.e., seems highly relevant to objectification, seems somewhat relevant to objectification, can't decide if it's relevant, or seems irrelevant to objectification). Only items that achieved highly relevant to objectification from at least $80 \%$ of raters were retained. These 29 -items were then included in the Interpersonal Objectification scale administered to participants using a Likert-type scale that ranged from strongly disagree to strongly agree (see Appendix B).

Following data collection, a parallel analysis was conducted to determine the scale's structure and optimal number of factors to retain (Hayton, Allen, \& Scarpello, 2004). A threefactor model was indicated because three factors exhibited eigenvalues that exceeded the 95th percentile, based on 500 random data sets with the same number of variables and sample size. 
Subsequently, a principle components analysis (PCA) with varimax rotation was conducted with the model restricted to three factors. Fourteen items were removed because they either had factor loading of less than .50 or loaded on multiple factors. This resulted in a three-factor model that was supported by a parallel analysis, scree plot, and the Kaiser criterion of an eigenvalue greater than one (Cattell, 1966; Kaiser, 1958). The interpersonal objectification scale includes subscales of perspective-taking ( 7 items, $\alpha=.77$ ), sexual gratification ( 5 items, $\alpha=.77$ ), and instrumentality ( 3 items, $\alpha=.51$ ). The perspective-taking subscale included all reverse-scored items such as, "when I am involved or getting involved with someone, I want to understand on an intimate level who they are as a person." The sexual gratification subscale included items such as, "If a person is not getting their sexual needs met in their primary relationship, it is okay to get them met elsewhere." The instrumentality subscale included items such as, "in life, we all basically use other people as a means to our own ends." Although the instrumentality subscale demonstrated the lowest reliability, it also captured theoretically essential aspects of interpersonal objectification, and thus these items were retained. The final scale utilized for analyses included all 15 items, and demonstrated adequate reliability, $\alpha=.78$ (see Appendix C).

Next, evidence for construct validity was explored by examining correlations with related constructs. The interpersonal objectification score demonstrated a strong positive correlation with objectification items used by Gruenfeld et al. (2008) $(\mathrm{r}=.42, \mathrm{p}<.001)$, Psychopathy $(\mathrm{r}=$ $.58, \mathrm{p}<.001)$ and Machiavellianism $(\mathrm{r}=.41, \mathrm{p}<.001)$, but a weaker correlation with $\operatorname{Determinism}(\mathrm{r}=.24, \mathrm{p}<.001)$ and $\operatorname{Narcissism}(\mathrm{r}=.19, \mathrm{p}<.001)$. There was no apparent association between interpersonal objectification and Free Will $(r=-.04, p=.32)$. Evidence for criterion validity is provided by a strong negative correlation between interpersonal objectivity and the number of attention-check items that were correctly registered $(r=-.35, p<.001)$ 
suggesting that those who reported being willing to objectify others are less likely to demonstrate conscientious survey completion.

\section{Dark Triad}

The Short Dark Triad scale (SD3) is a self-report inventory that measures dark personality traits that together denote the Dark Triad (Jones \& Paulhus, 2014). The questionnaire includes 27 items on a 5-point Likert-type scale with options ranging from disagree strongly and agree strongly. Nine items make up the Machiavellianism, narcissism, and psychopathy subscales. The Machiavellianism subscale focused on reputation, cynicism, coalition building, and strategic calculation, for example, "I like to use clever manipulation to get my way." The narcissism subscale included items that centered around entitlement, grandiosity, and exhibitionism (e.g., "I insist on getting the respect I deserve"). The psychopathy subscale measured included items that focused on antisocial behavior, erratic lifestyle, callous affect, and short-term manipulation (e.g., “people often say I'm out of control”) (see Appendix D). According to Jones and Paulhus (2014), support for validity was established as the subscales successfully mapped onto established inventories: the Dirty Dozen (Jonason \& Webster, 2010), the Self-Report Psychopathy Scale (SRP-III; Paulhus, Neumann, \& Hare, in press; Williams, Paulhus, \& Hare, 2007), the Mach-IV (Christie \& Geis, 1970), the Narcissistic Personality Inventory (NPI; Raskin \& Hall, 1979), and the International Personality Item Pool-Interpersonal Circumplex (IPIP-IPC; Markey \& Markey, 2009). For this study, Cronbach coefficient alphas ranged from .68 and .75 for the three subscales.

\section{Objectification}

Gruenfeld and colleagues (2008) created a scale to measure objectification within work relationships. The items used in this scale are equivalent to the central features of objectification 
proposed by Nussbaum (1995). Participants were presented with two prompts; the subordinate target condition involved a professional relationship that was hierarchical, whereas the peer target condition involved a professional relationship that was not hierarchical. Participants were then asked to report their agreement of statements related to their perception of their work relationship (e.g., "I think more about what this person can do for me than what I can do for him/her"). This questionnaire included 10 self-report items on a 7-point Likert-type scale with items ranging from disagree strongly to agree strongly (see Appendix E). In the present study, Cronbach's coefficient alpha was .77.

\section{Procedure}

Following approval by Illinois State University's Institutional Review Board (IRB), participants were recruited using an online system, SONA, run by the Illinois State University Department of Psychology. Extra credit for psychology courses was offered as compensation for these students. Additional participants were recruited through a university-wide email sent to students enrolled at the university. This email included a brief explanation of the study and an anonymous Qualtrics link. These participants had the opportunity to enter a raffle for a chance to win a \$20 Amazon gift card. Following recruitment, participants were prompted to read and electronically sign an informed consent form. From there, participants completed a set of questionnaires including the FWI, the IO, the SD3, and the OS. After all questionnaires were completed, participants were debriefed on the purpose of the study.

\section{Data Analysis Plan}

Descriptive statistics for study variables were analyzed first. Bivariate correlations between belief in free will and determinism, interpersonal objectification, and the Dark Triad were examined using Pearson correlation analyses. Correlation analyses were used to test the 
first four hypotheses of this study, which predicted that belief in determinism would be positively associated with objectification and the Dark Triad (i.e., narcissism, psychopathy, and Machiavellianism).

To examine Hypothesis 5, which predicted that the association between determinism and the Dark Triad would be mediated by interpersonal objectification, I used PROCESS analyses (Hayes, 2018). This analytic procedure assessed the indirect effects of belief in determinism and narcissism, psychopathy, and Machiavellianism through interpersonal objectification. I used the determinism subscale of the FWI, the total score from the 15-item IO scale, and the respective subscales from the SD3 to analyze three mediation models. The criterion for statistical significance was $\mathrm{p}<.05$.

For each of the three indirect effects, I used bootstrapping to determine the significance of indirect effects. The process of bootstrapping involves drawing, with replacement, 5,000 samples of $\mathrm{N}=608$ from the sample of 608 participants, which is used as a population reservoir. Hayes (2018) PROCESS analyses computed unstandardized indirect effects of each bootstrapped sample. These 5,000 samples were used to determine a $95 \%$ confidence interval for each of the three outcome variables: Machiavellianism, narcissism, and psychopathy. 


\section{CHAPTER IV: RESULTS}

Participants completed four questionnaires to assess their general levels of belief in free will and determinism (FWI), interpersonal objectification (IO and OS), and dark personality traits (SD3). Table 1 shows the respective range, means, and standard deviations for the scales and subscales of the present study's measures.

Table 1.

Means and Standard Deviations for Belief in Free Will, Interpersonal Objectification, and The Dark Triad Measures

\begin{tabular}{llll}
\hline Variable & & Total & \\
\hline & Range & $M$ & $S D$ \\
\hline FWI-Free Will & $1-7.00$ & 4.60 & 1.19 \\
FWI-Determinism & $1-7.00$ & 3.35 & 1.16 \\
IO-Perspective-Taking & $1-7.00$ & 1.83 & 0.71 \\
IO-Sexual & $1-5.80$ & 1.58 & 0.78 \\
IO-Instrumentality & $1-6.67$ & 3.32 & 1.12 \\
IO-Total & $1-4.40$ & 2.05 & 0.62 \\
OS & $1-6.30$ & 3.31 & 0.87 \\
SD3-Machiavellianism & $1-5.00$ & 2.84 & 0.59 \\
SD3-Narcissism & $1-4.78$ & 2.81 & 0.53 \\
SD3-Psychopathy & $1-4.11$ & 2.06 & 0.58 \\
\hline Note. FWI = Free Will Inventory; IO = Interpersonal Objectification Scale; OS = Objectification \\
Scale; SD3 = Short Dark Triad. & & & \\
& & & \\
\hline
\end{tabular}




\section{Main Analyses}

Correlations were computed to examine the relations among belief in free will, belief in determinism, interpersonal objectification, and the Dark Triad (see Table 2). First, belief in free will was only positively associated with belief in determinism and narcissism. Belief in free will was negatively associated with the interpersonal objectification total, the perspective-taking and instrumentality subscales of the interpersonal objectification scale, the objectification scale, and psychopathy, though none of these correlations were statistically significant.

Belief in determinism was positively correlated with interpersonal objectification, as demonstrated by the positive associations between belief in determinism and the interpersonal objectification subscales (perspective-taking, sexual, and instrumentality) and the interpersonal objectification total. Belief in determinism was also positively correlated with the objectification scale assessing objectification and power within work relationships. These correlational findings provide support for Hypothesis 1A, which was that belief in determinism would be positively associated with individuals' propensity to objectify others.

There were also positive correlations between belief in determinism and the Dark Triad. Belief in determinism was positively correlated with measures of narcissism, psychopathy, and most strongly correlated with Machiavellianism. Belief in determinism was correlated with narcissism, providing support for Hypothesis 2, which was that belief in determinism would positively correlate with individuals' propensity to be narcissistic. Belief in determinism was also positively associated with psychopathy, which provided support for Hypothesis 3, predicting that belief in determinism would be positively associated with individuals' propensity to be psychopathic. Finally, belief in determinism was positively correlated with Machiavellianism, 
providing support for Hypothesis 4, predicting that belief in determinism would be positively associated with individuals' propensity to be Machiavellian and manipulate others. 
Table 2 .

Correlations among Scores on Belief in Free Will, Interpersonal Objectification, and The Dark Triad Measures

\begin{tabular}{|c|c|c|c|c|c|c|c|c|c|c|}
\hline & 1 & 2 & 3 & 4 & 5 & 6 & 7 & 8 & 9 & 10 \\
\hline 1. FWI-Free Will & - & & & & & & & & & \\
\hline 2. FWI-Determinism & $.12 * *$ & - & & & & & & & & \\
\hline 3. IO-Perspective-Taking & -.05 & $.14 * *$ & - & & & & & & & \\
\hline 4. IO-Sexual & .00 & $.20 * *$ & $.46^{* *}$ & - & & & & & & \\
\hline 5. IO-Instrumentality & -.05 & $.21 * *$ & $.20 * *$ & $.30 * *$ & - & & & & & \\
\hline 6. IO-Total & -.04 & $.24^{* *}$ & $.80 * *$ & $.78 * *$ & $.61 * *$ & - & & & & \\
\hline 7. OS & -.04 & $.17 * *$ & $.31 * *$ & $.30 * *$ & $.34 * *$ & $.42 * *$ & - & & & \\
\hline 8. SD3-Machivellianism & .06 & $.30 * *$ & $.23 * *$ & $.29 * *$ & $.44 * *$ & $.41 * *$ & $.39 * *$ & - & & \\
\hline 9. SD3-Narcissism & $.09 *$ & $.17 * *$ & .07 & $.19 * *$ & $.18 * *$ & $.18^{* *}$ & $.25 * *$ & $.33 * *$ & - & \\
\hline 10. SD3-Psychopathy & -.04 & $.20 * *$ & $.43 * *$ & $.46^{* *}$ & $.39 * *$ & $.58 * *$ & $.35 * *$ & $.52 * *$ & $.31 * *$ & - \\
\hline
\end{tabular}

Note. FWI = Free Will Inventory; IO = Interpersonal Objectification Scale; OS = Objectification Scale; SD3= Short Dark Triad. *p $<$ $.05 . * \mathrm{p}<.01$ 
Finally, I tested Hypothesis 5, which was that interpersonal objectification would mediate the relationship between the belief in determinism and the Dark Triad personality traits. There were significant pathways between belief in determinism and narcissism $(b=.08, t(565)=4.23$, $p<.001)$, psychopathy $(b=.10, t(563)=4.89, p<.001)$, and Machiavellianism $(b=.16, t(565)$ $=7.63, p<.001)$.

\section{Narcissism}

In support of the hypothesis that objectification would mediate the association between belief in determinism and narcissism, the bootstrapped indirect effect of belief in determinism on narcissism through interpersonal objectification was statistically significant, $b=.02,95 \% \mathrm{CI}=$ $[.01, .03]$. This suggests that the relationship between belief in determinism and individuals' propensity to be narcissistic was mediated by interpersonal objectification (see Figure 2); however, variability remained between belief in determinism and narcissism. Results demonstrated that belief in determinism and interpersonal objectification accounted for $5 \%$ of the variance in narcissism, $F(2,564)=15.21, p<.001, R^{2}=.05$.

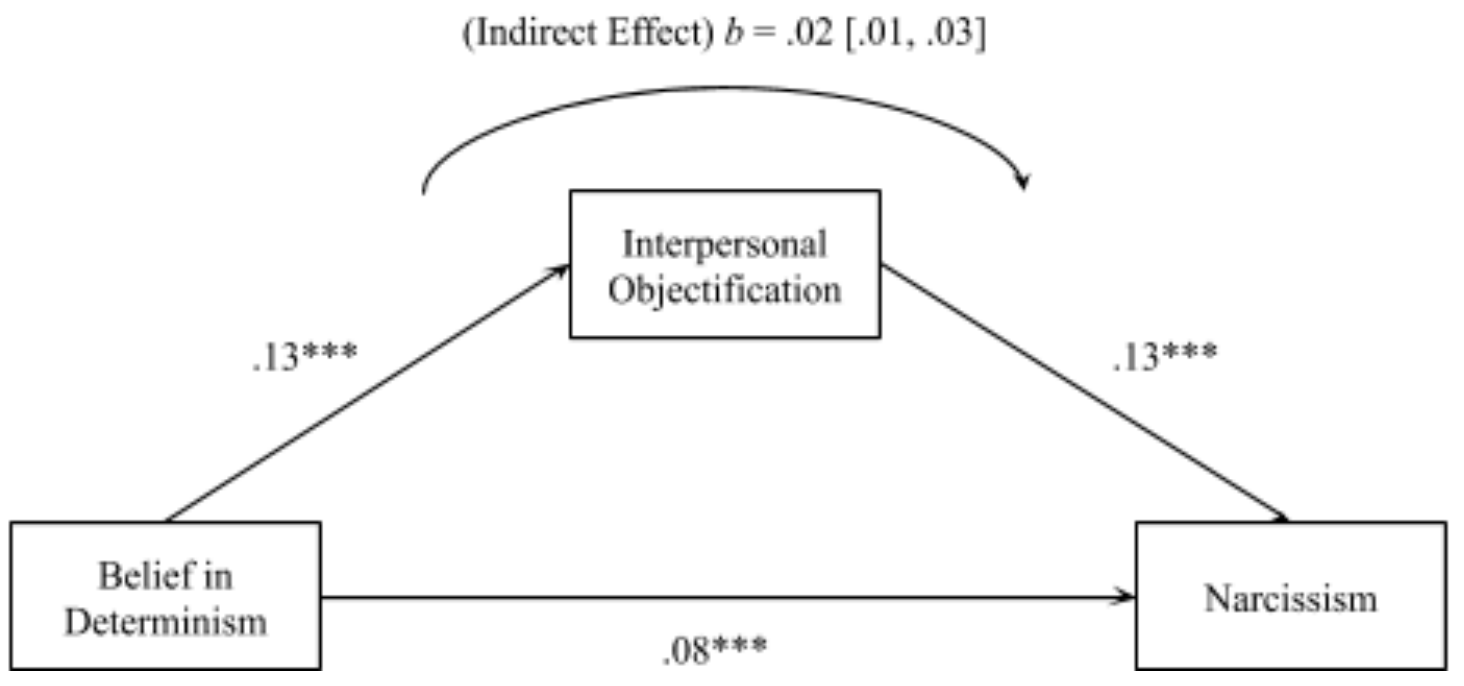


Figure 2. Unstandardized regression coefficients for the mediation analysis of belief in determinism, interpersonal objectification, and narcissism. CI = confidence interval. $* * * p<.001$.

\section{Psychopathy}

In support of the hypothesis that objectification would mediate the association between belief in determinism and psychopathy, the bootstrapped, unstandardized indirect effect of belief in determinism on psychopathy through interpersonal objectification was statistically significant, $b=.07,95 \% \mathrm{CI}=[.04, .10]$. The relationship between belief in determinism and individuals' propensity to be psychopathic was also mediated by interpersonal objectification (see Figure 3 ). Similar to the narcissism model, variability remained between belief in determinism and psychopathy, suggesting that there may be other aspects of deterministic beliefs — other than interpersonal objectification - that account for psychopathic traits. Results demonstrated that belief in determinism and interpersonal objectification accounted for $33 \%$ of the variance in psychopathy, $F(2,562)=138.50, p<.001, R^{2}=.33$.

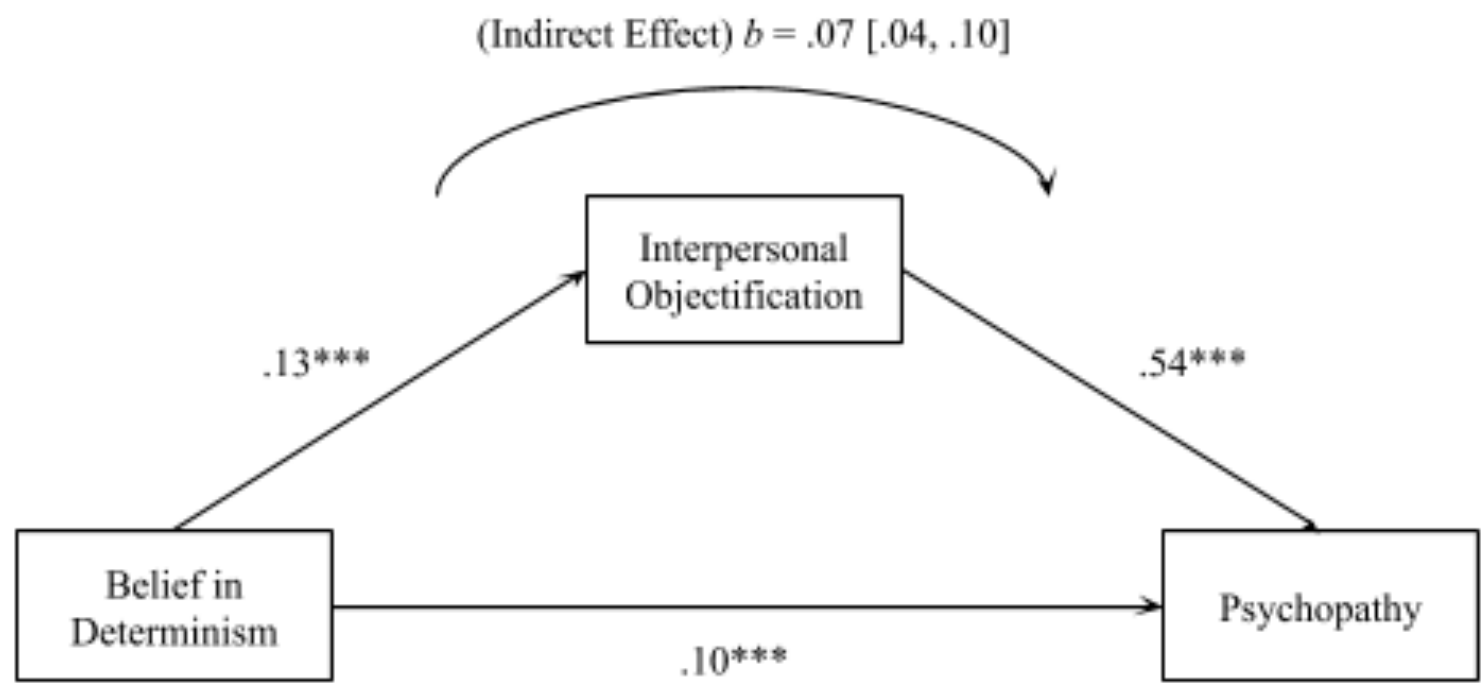


Figure 3. Unstandardized regression coefficients for the mediation analysis of belief in determinism, interpersonal objectification, and psychopathy. $\mathrm{CI}=$ confidence interval. $* * * p<.001$.

\section{Machiavellianism}

In support of the hypothesis that objectification would mediate the relation between belief in determinism and Machiavellianism, the bootstrapped, unstandardized indirect effect of belief in determinism on Machiavellianism through interpersonal objectification was statistically significant, $b=.04,95 \% \mathrm{CI}=[.02, .07]$, see Figure 4. Similar to the other two models, variability remained between belief in determinism and Machiavellianism, suggesting that other aspects than interpersonal objectification may influence Machiavellianism. Results demonstrated that belief in determinism and interpersonal objectification accounted for $21 \%$ of the variance in Machiavellianism, $F(2,564)=76.38, p<.001, R^{2}=.21$.

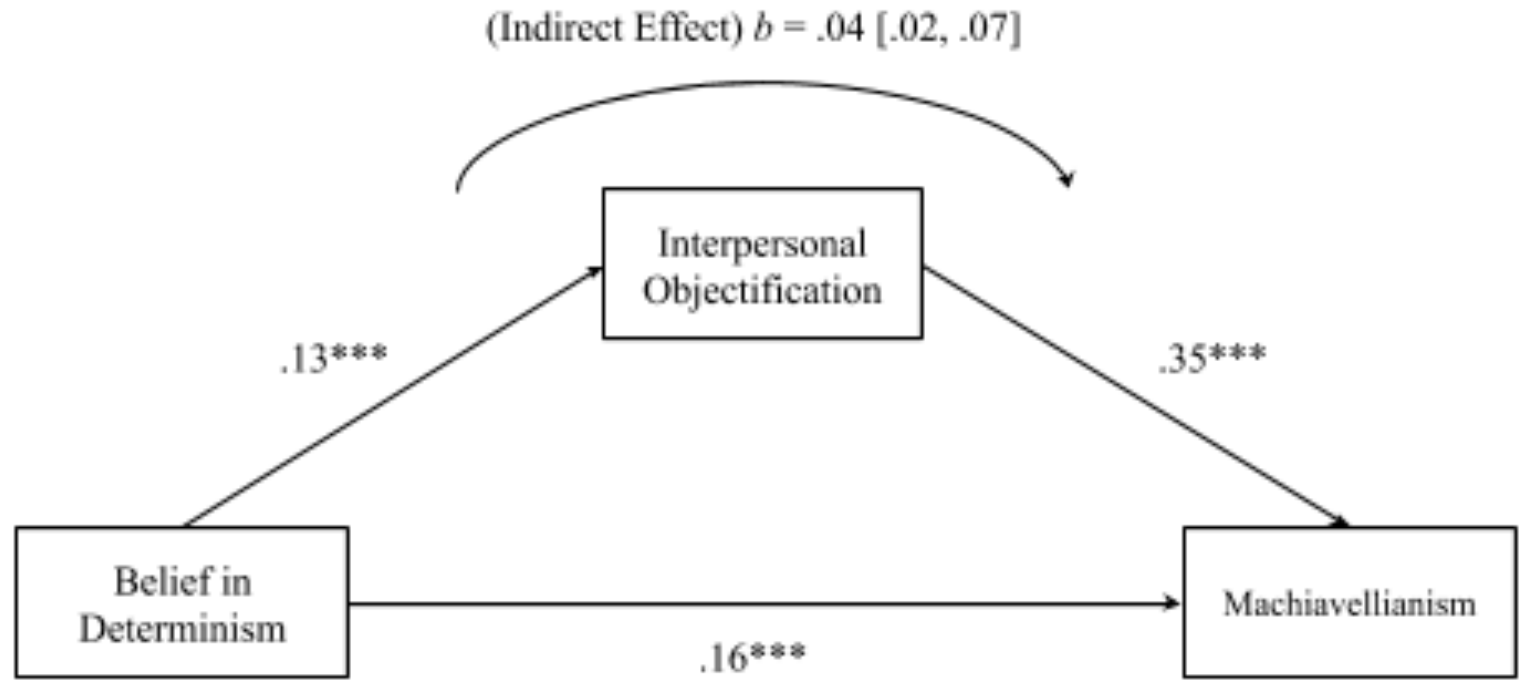

Figure 4. Unstandardized regression coefficients for the mediation analysis of belief in determinism, interpersonal objectification, and Machiavellianism. CI = confidence interval. $* * * p<.001$. 


\section{CHAPTER V: DISCUSSION}

Research has demonstrated that belief in determinism can negatively affect behavior because this belief requires a decreased need for volition and self-control (Alquist, Ainsworth, \& Baumeister, 2013; Baumeister, Masicampo, \& DeWall, 2009; Stillman \& Baumeister, 2010; Vohs \& Schooler, 2008). In support of Bergner and Ramon's (2013) notion that perceiving that one has "no choice in the matter" is associated with disregarding one's personal responsibility and increased moral disengagement, the present study's empirical findings suggest that another possibly salient accompaniment of belief in determinism is the likelihood to objectify others and exhibit antisocial tendencies. Specifically, the present study examined the association between beliefs in determinism, interpersonal objectification, and self-reported dark personality traits. The present study's results lend evidence to previous theoretical and empirical work that suggest that deterministic beliefs may either help motivate or rationalize antisocial behavior.

The results of this study do not demonstrate a causal relationship between belief in determinism, interpersonal objectification, or dark personality traits. They simply indicate empirical associations between these constructs. Overall, results provide evidence that deterministic ideologies are associated with unfavorable interpersonal tendencies. However, it is possible that, if any causal possibilities exist with respect to this association, these may exist in the opposite direction (i.e., maladaptive personality traits influencing maladaptive ideologies.

Results supported my first two hypotheses, namely that belief in free will would be negatively associated with objectification and that belief in determinism would be positively associated with interpersonal objectification. Specifically predicting that with no behavioral alternatives to consider, individuals may feel less accountable for their actions (Feldman et al., 2016), and in turn, objectify others based on their utility. This is an important addition to the 
existing literature. Although multiple studies have shown that belief in free will is closely related to prosocial behavior (Baumeister, Masicampo, \& DeWall, 2009) and socially desirable beliefs (Vonasch \& Baumeister, 2012), the present study adds to this literature by providing evidence that beliefs in determinism are also linked to the tendency to objectify others, rather than viewing them as autonomous beings.

The present study also found support for hypotheses that deterministic beliefs would be associated with increased antisocial tendencies. Results of this study support these claims, as belief in determinism was linked to narcissism, psychopathy, and Machiavellianism. Within established literature, belief in determinism has been empirically associated with vindictive and antisocial behavior (Caspar, Vuillaume, Magalhães De Saldanha da Gama, \& Cleeremans, 2017), diminished self-control (Alquist, Ainsworth, \& Baumeister, 2013), limited impulse control (Cave, 2016), and aggression (Baumeister, Masicampo, DeWall, 2009).

While I hypothesized that deterministic beliefs would be positively associated with narcissism, and belief in free will would be negatively associated with narcissism, results indicated that both beliefs were positively linked to narcissism. This finding, while unprecedented, is consistent with previous research that demonstrated a link between deterministic beliefs and narcissism, as belief in determinism could potentially serve as a catalyst for impulsive selfishness and the advancement of one's own self-interest (Protzko, Ouimette, \& Schooler, 2016). It was somewhat unexpected that free will beliefs demonstrated a similar relation with narcissism. In contrast to the much of the research cited above, Nadelhoffer and Tocchetto (2013) have put forth evidence suggesting that believing in free will may be associated with tendencies toward right-wing authoritarianism and just world beliefs. Future research could investigate these apparently contradictory results and implications. 
In support of my hypothesis, belief in determinism was empirically associated with psychopathic tendencies. It may be possible that individuals identifying with deterministic beliefs might demonstrate psychopathic tendencies and deem ramifications of their impulsive behavior a matter of inevitability, thereby disregarding moral responsibility. Results in the present study support this notion that belief in determinism is linked to antisocial proneness (Stillman \& Baumeister, 2010; Vohs \& Schooler, 2008). However, contrary to my hypothesis, belief in free will was not associated with psychopathic tendencies. While previous research demonstrates a link between belief in free will, prosocial behavior, and a reduction of disruptive behavior (Bergner \& Ramon, 2013), the present study's results are less conclusive—as there was no statistically significant relationship.

In support of my hypothesis, belief in determinism was associated with greater trait Machiavellianism and the tendency to manipulate others through dismissal of morality. This fourth hypothesis was developed based on the mutual dismissal of morality between belief in determinism and Machiavellianism. Bergner and Ramon (2013) argue that belief in determinism lends itself to the general disregard of morality. Specifically noting that deterministic beliefs involve little to no agency, which may result in diminished responsibility and, in turn, no morality to consider. Individuals exhibiting Machiavellian characteristics typically view others as objects to be manipulated while neglecting conventional morality.

I hypothesized that interpersonal objectification would represent a tendency that could account for the positive association between one's belief in determinism and their Dark Triad personality traits. Results also supported the hypothesized mediation model, as interpersonal objectification partially mediated the relationship between deterministic beliefs and dark personality traits. The maladaptive ideology of determinism and the maladaptive personality 
traits of narcissism, psychopathy, and Machiavellianism may share a common themeobjectifying other human beings. Interpersonal objectification and dark personality traits fall on continuums that include adaptive and maladaptive manifestations that may be problematic (Baumeister \& Brewer, 2012; Paulhus \& Williams, 2002; Rector, 2017). The mediation model in this study indicated that belief in determinism was empirically linked to the Dark Triad personality traits, which may be related to deterministic beliefs that allow for the disavowal of others' humanity.

\section{Implications}

This research has implications for our theoretical understanding of belief in free will and determinism. Psychologists argue that free will beliefs are linked to experience with and assumptions about human agency that allow for self-control and rational choice related to moral responsibility (Nahmias, Morris, Nadelhoffer, \& Turner, 2005; Wegner, 2004). By reason of perceived control, belief in free will has been accepted as an adaptive, ungrounded belief (cf. Smithdeal, 2016). Sarkissian et al. (2010) found that, through intuition and shared experience, most believe our universe is indeterministic and moral responsibility is incompatible with determinism. Free will beliefs are embedded within Western religion, philosophy, and legal precedent (Baumeister et al., 2009; Rakos, Laurene, Skala, \& Slane, 2008), it is unclear how or why individuals come to hold deterministic beliefs. Future research might explore various biological, psychological, and social factors that facilitate an individual's belief in determinism.

The research and findings of this study informs and strengthens our understanding of how belief in determinism, objectification, and dark personality traits may be related to unfavorable outcomes. Belief in determinism appears to be associated with decreased personal moral responsibility and increased self-reported antisocial tendencies. However, the present study did 
not find conclusive links between beliefs in free will and interpersonal objectification and Dark Triad personality traits. In fact, the correlation between beliefs in free will and determinism was positive (albeit very small, $r=.12$ ). This suggests that many people may hold somewhat theoretically conflicting views about the nature of their personal agency at the same time (cf. Hannikainen et al., 2019; Nichols \& Knobe, 2007). Understanding how people resolve these internal conflicts (or not) may be useful empirical work that provides insight into the extent to which people emphasize, ignore, or contextualize one ideology that seemingly contradicts another that they hold.

This research also establishes a link between belief in determinism and interpersonal objectification. Objectification has been understood as the seeing and treating others as objects through denial of their humanity, ultimately undermining the target's personhood. Research suggests that targets of objectification typically experience guilt, shame, reduced self-esteem, depression, feelings of worthlessness, and potential self-objectification (i.e., the preoccupation with one's appearance, resulting in frequent body surveillance) as a result of being objectified (Orehek \& Weaverling, 2017). Recognizing that interpersonal objectification, at its extreme, involves dehumanization and violence has very straightforward and obvious implications for morality.

Belief in determinism may be one ideological orientation that encourages selfexoneration and moral disengagement. Identifying correlations among belief in determinism and negative outcomes does not necessarily mean that this belief will immediately lead to deviant or maladaptive behavior (Smithdeal, 2016). Bandura (2002) argues that moral agency is a selfregulatory process linking moral reasoning and moral action. This self-regulatory process encourages humane behavior through moral self-sanctions and allows inhumane behavior 
through self-exonerations by way of moral disengagement. Moral disengagement is a matter of selective activation and disengagement using moral justification, diffusion or displacement of responsibility, minimizing or distorting harm inflicted, or dehumanizing and blaming the victim (Bandura, 2002). Bandura's (1986) social cognitive theory proposes an interactionist perspective that views moral behavior as a product of shared cognitive, affective, and social influences. Belief in determinism may be an ideological belief that is associated with an individuals' inclination to disengage morally. Future research might consider the association between deterministic beliefs and a tendency towards moral disengagement.

This research has implications for the clinical treatment of perpetrators and victims of objectification and maladaptive personality traits. Recognizing potential underlying factors of objectification and dark personality traits include dismissal of or disregard for moral responsibility may be a useful focal point for intervention. Feminist, existential, and choice therapeutic approaches may be effective interventions for enhancing individuals' moral reasoning through acceptance of responsibility and awareness of free will. Individuals exhibiting dark personality traits may also benefit from therapeutic interventions that enhance impulse control and behavioral inhibition. Victims of objectification may benefit from psychotherapy that challenges their internalized guilt and shame, reduced self-esteem, and feelings of worthlessness that contribute to depression and self-objectification.

This study also has implications for future research and measurement of interpersonal objectification. Based on the limited research and lack of established measures of interpersonal objectification, previous research has used variations of self-objectification scales to measure the objectification of others (Bevens \& Loughnan, 2019). The newly developed interpersonal objectification measure employed in this study included only items that had been rated very 
highly by a panel of trained graduate student raters as capturing the concept of objectification. Thus, there are grounds for assuming that, in keeping with the classical criterion of construct validity that a measure's "construct validity is the degree to which a test measures what it claims, or purports, to be measuring" (Brown, 1996, p. 231), that this scale measures up in this regard. However, on more enhanced statistical analyses undertaken, it demonstrated only modest validity. Overall, there is some reason to believe that this instrument lays the foundation for future research investigating the presence and consequences of interpersonal objectification.

\section{Limitations and Future Directions}

One limitation of this research is its cross-sectional nature. The present study does not differentiate between cause and effect. The correlational analyses used within this study examined the association between variables, assuming directional correlations among belief in determinism, objectification, and dark personality. Specifically predicting that belief in determinism would lead to increased objectification and manifestation of dark personality traits. However, this study does not examine the potential for a transactional relationship among these variables. Future research might explore bidirectional associations among belief in determinism and objectification, and belief in determinism and the Dark Triad, to consider investigation of this belief as a justification for maladaptive attitudes or behaviors. Additional research may also consider using a longitudinal or experimental design to investigate the links between deterministic beliefs and undesirable outcomes.

An additional limitation of the present study is the generalizability of these findings. Although previous research has demonstrated a surprising level of cross-cultural convergence with regards to free will beliefs and incompatibilism between determinism and moral responsibility (Sarkissian, Chatterjee, De Brigard, Knobe, Nichols, \& Sirker, 2010), the 
homogeneity of this study's sample may impede the generalizability of these results. It is also possible that college students respond differently to the questionnaires used in this study due to the relatively abstract theoretical concepts considered. Future research could explore individual and cultural variations in belief in determinism, and how this may influence the association between conditions for belief in determinism and moral responsibility.

A final limitation of the present study is the measure used to assess interpersonal objectification. The measure created for the purposes of this study was developed based on the seven philosophical features proposed by Martha Nussbaum (1995). Following item generation, psychology graduate students were provided a detailed explanation of objectification in contrast to treating people as people to establish construct validity. Unfortunately, an exploratory factor analysis revealed that only three factors remained (perspective-taking, sexual gratification, and instrumentality). A follow-up study should be conducted to improve validity and reliability of this measure.

\section{Conclusion}

The present study contributes to existing literature suggesting that belief in determinism is linked to maladaptive attitudes and behavior. One's belief in determinism was found to be associated with a greater tendency to objectify others, which in turn may be linked to overarching darker personality traits such as narcissism, psychopathy, and Machiavellianism. Believing that the universe is predestined to be the way it is and that one does not have the ability to control their own decisions and actions may lead some individuals down a maladaptive and manipulative path. They may reduce others to objects, rather than viewing them as subjects of their own stories and may even find themselves engaging in darker and more destructive patterns. 


\section{REFERENCES}

Alquist, J. L., Ainsworth, S. E., \& Baumeister, R. F. (2013). Determined to conform: Disbelief in free will increases conformity. Journal of Experimental Social Psychology, 29, 80-86.

American Psychiatric Association. (2013). Diagnostic and statistical manual of mental disorders (5th ed.). Arlington, VA: American Psychiatric Publishing.

Bandura, A. (1986). Social foundations of thought and action: A social cognitive theory. Englewood Cliffs, NJ: Prentice-Hall.

Bandura, A. (2002). Selective moral disengagement in the exercise of moral agency. Journal of Moral Education, 31, 101-119.

Baumeister, R. F. (2008). Free will in scientific psychology. Perspectives on Psychological Science, 3,14-19.

Baumeister, R. F., \& Brewer, L. E. (2012). Believing versus disbelieving in free will: Correlates and consequences. Social and Personality Psychology Compass 6, 736-745.

Baumeister, R. F., Masicampo, E. J., \& DeWall, C. N. (2009). Prosocial benefits of feeling free: Disbelief in free will increases aggression and reduces helpfulness. Personality and Social Psychology Bulletin, 35, 260-268.

Beller, J., \& Bosse, S. (2017). Machiavellianism has a dimensional latent structure: Results from taxometric analyses. Personality and Individual Differences, 113, 57-62.

Bergner, R. M., \& Ramon, A. (2013). Some implications of beliefs in altruism, free will, and nonreductionism. The Journal of Social Psychology, 153, 598-618

Bevens, C. L., \& Loughnan, S. (2019). Insights into men's sexual aggression toward women: Dehumanization and objectification. Sex Roles, 81, 713-730. 
Brown, J. D. (1996). Testing in language programs. Upper Saddle River, NJ: Prentice Hall Regents, pp. 231-249.

Cahill, A. J. (2011). Overcoming objectification: A carnal ethics. New York, NY: Routledge.

Carmody, P. C., \& Gordon, K. C. (2014). Mere civility, or genuine forgiveness? Prosocial consequences of belief in free will. Interpersonal: An International Journal on Personal Relationships, 8, 245-256.

Carey, J. M., \& Paulhus, D. L. (2013). Worldview implications of believing in free will and/or determinism: Politics, morality, and punitiveness. Journal of Personality, 81, 130-141.

Caspar, E. A., Vuillaume, L., Magalhães De Saldanha da Gama, P. A., \& Cleeremans, A. (2017). The influence of (dis)belief in free will on immoral behavior. Philosophical Psychology, $8,1-9$

Cave, S. (2016). There's no such thing as free will. The Atlantic. Retrieved from https://www.theatlantic.com/magazine/archive/2016/06/theres-no-such-thing-as-freewill/480750/

Christie, R., \& Geis, F. L. (1970). Studies in Machiavellianism. New York, Academic Press, 1970.

Cleckley, H. (1950). The mask of sanity (2 $2^{\text {nd }}$ ed.). St. Louis, MO: Mosby.

Cleckley, H. (1984). The mask of sanity (6 ${ }^{\text {th }}$ ed.) St. Louis, MO: Mosby.

Feldman, G. Baumeister, R. F., \& Wong, K. F. E. (2014). Free will is about choosing: The link between choice and the belief in free will. Journal of Experimental Social Psychology, 55, 239-245.

Feldman, G., Wong, K. F. E., \& Baumeister, R. F. (2016). Bad is freer than good: Positivenegative asymmetry in attributions of free will. Consciousness and Cognition, 42, 26-40. 
Fast, I. (1985). Infantile narcissism and the active infant. Psychoanalytic Psychology, 2, 153-170.

Genschow, O., Rigoni, D., \& Brass, M. (2017). Belief in free will affects causal attributions when judging others' behavior. Proceedings of the National Academy of Sciences, 114, 10071-10076.

Glannon, W. (2011). Diminishing and enhancing free will. AJOB Neuroscience 2, 15-26.

Gruenfeld, D. H., Inesi, M. E., Magee, J. C., \& Galinsky, A. D. (2008). Power and objectification of social targets. Journal of Personality and Social Psychology, 95, 111-127.

Hare, R. D. (1991). The Hare Psychopathy Checklist-Revised. Toronto, ON: Multi-Health Syst.

Hare, R. D. (2003). The Hare Psychopathy Checklist-Revised. Toronto, ON: Multi-Health Syst.

Hare, R. D. (1999). Without conscience: The disturbing world of the psychopaths among us. New York, NY: Guilford Press.

Hare, R. D., \& Neumann, C. S. (2008). Psychopathy as a clinical and empirical construct. Annual Review of Clinical Psychology, 4, 217-246.

Hart, W., Richardson, K., Tortoriello, G., \& Tullett, A. (2017). Strategically out of control: A self-presentational conceptualization of narcissism and low self-control. Personality and Individual Differences, 114, 103-107.

Hayes, A. F. (2018). Introduction to mediation, moderation, and conditional process analysis (2nd ed.). New York, NY: The Guilford Press.

Heflick, N. A., Goldenberg, J. L., Cooper, D. P., \& Puvia, E. (2011). From women to objects: Appearance focus, target gender, and perceptions of warmth, morality, and competence. Journal of Experimental Social Psychology, 47, 572-581.

Jones, D. N., \& Paulhus, D. L. (2014). Introducing the short dark triad (SD3): A brief measure of dark personality traits. Assessment 21, 28-41. 
Karandikar, S., Kapoor, H., Fernandes, S., \& Jonason, P. K. (2019). Predicting moral decisionmaking with dark personalities and moral values. Personality and Individual Differences, 140, 70-75.

Kowalski, C. M., Kwiatkowska, K., Kwiatkowska, M. M., Ponikiewska, K., Rogoza, R., Schermer, J. A. (2018). The dark triad traits and intelligence: Machiavellians are bright, and narcissists and psychopaths are ordinary. Personality and Individual Differences, $135,1-6$.

Krizan, Z., \& Herlache, A. D. (2018). The narcissism spectrum model: A synthetic view of narcissistic personality disorder. Personality and Social Psychology Review, 22, 3-31.

Loughnan, S., Baldissarri, C. Spaccatini, F., \& Elder, L. (2017). Internalizing objectification: Objectified individuals see themselves as less warm, competent, moral, and human. British Journal of Social Psychology 56, 217-232.

Loughnan, S., Haslam, N., Murnane, T., Vaes, J., Reynolds, C., \& Suitner, C. (2010). Objectification leads to depersonalization: The denial of mind and moral concern to objectified others. European Journal of Social Psychology, 40, 709-717.

MacDonald, P. (2014). Narcissism in the modern world. Psychodynamic Practice, 20, 144-153.

Maddux, J. E., \& Winstead, B. A. (2016). Psychopathology: Foundations for a contemporary understanding (4 ${ }^{\text {th }}$ Ed.). New York, NY: Routledge

Magnani, L. (2012). Morality and psychopathic criminals. Ethiocentrism, mental incapacity, free will, and the fear of decriminalization. Rivista Internazionale Di Filosofia e Psicologia, $3,26-35$.

Malesza, M., \& Kaczmarek, M. C. (2018). Grandiose narcissism versus vulnerable narcissism and impulsivity. Personality and Individuals Differences, 126, 61-65. 
Maxwell, B. \& Le Sage, L. (2009). Are psychopaths morally sensitive? Journal of Moral Education, 38, 75-91.

Mielimaka, M., Ogrodniczuk, J. S., Kealy, D., Cheek, J., \& Joyce, A. S. (2018). Narcissism and interpersonal problems among psychiatric outpatients. The Journal of Nervous and Mental Disease, 206, 711-715

Moynihan, A. B., Igou, E. R., \& van Tilburg, W. A. P. (2017). Free, connected, and meaningful: Free will beliefs promote meaningfulness through belongingness. Personality and Individual Differences, 107, 54-65.

Müller, T., \& Placek, T. (2018). Defining determinism. The British Journal for the Philosophy of Science 69, 215-252.

Nadelhoffer, T., Shepard, J., Nahmias, E., Sripada, C., \& Ross, L. T. (2014). The free will inventory: Measuring beliefs about agency and responsibility. Consciousness and Cognition, 25, 27-41.

Nahmias, E., Morris, S., Nadelhoffer, T., \& Turner, J. (2005). Surveying freedom: Folk intuitions about free will and moral responsibility. Philosophical Psychology, 18, 561584.

Nichols, S., \& Knobe, J. (2007). Moral responsibility and determinism: The cognitive science of folk tuition. Noûs, 41, 663-685.

Nussbaum, M. C. (1995). Objectification. Philosophy \& Public Affairs, 24, 249-291. Retrieved from http://www.jstor.org/stable/2961930

Orehek, E., \& Weaverling, C. G. (2017). On the nature of objectification: Implications of considering people as means to goals. Perspectives on Psychological Science 12, 719 730. 
Papadaki, L. (2010). What is objectification? Journal of Moral Philosophy, 7, 16-36.

Paulhus, D., \& Carey, J. M. (2011). The FAD-Plus: Measuring lay beliefs regarding free will and related constructs. Journal of Personality Assessment, 93, 96-104.

Paulhus, D. L., \& Margesson, A. (1994). Free will and scientific determinism (FAD-4) scale. Vancouver: University of British Columbia. Unpublished instrument.

Paulhus, D. L., \& Williams, K. M. (2002). The dark triad of personality: Narcissism, Machiavellianism, and psychopathy. Journal of Research in Personality, 36, 556-563.

Persson, B. N. (2019). Searching for Machiavelli but finding psychopathy and narcissism. Personality Disorders: Theory, Research, and Treatment, 10, 235-245.

Pincus, A. L., \& Lukowitsky, M. R. (2010). Pathological narcissism and narcissistic personality disorder. Annual Review of Clinical Psychology, 6, 421-446.

Rakos, R. F., Laurene, K. R., Skala, S., \& Slane, S. (2008). Belief in free will: Measurement and conceptualization innovations. Behavior and Social Issues, 17, 20-39.

Raskin, R. N., \& Hall, C. S. (1979). A narcissistic personality inventory. Psychological Reports, $45,590$.

Rauthmann, J. F., \& Will, T. (2011). Proposing a multidimensional Machiavellianism conceptualization. Social Behavior and Personality, 39, 391-404.

Rector, J. M. (2017). The objectification spectrum: A new perspective on a familiar concept. The International Journal of Religion and Spirituality in Society, 7, 34-42.

Rotter, J. B. (1966). Generalized expectancies for internal versus external control of reinforcement. Monographs: General and Applied, 80, 1-28.

Sarkissian, H., Chatterjee, A., De Brigard, F., Knobe, J., Nichols, S., Sirker, S. (2010). Is belief in free will a cultural universal? Mind \& Language, 25, 346-358. 
Shah, J. Y., Kruglanski, A. W., \& Friedman, R. (2003). Goal systems theory: Integrating the cognitive and motivational aspects of self-regulation. In S. J. Spencer, S. Fein, M. P. Zanna, \& J. M. Olson (Eds.), Motivated Social Perception: The Ontario Symposium (pp. 247-275). Psychology Press.

Shariff, A. F., Greene, J. D., Karremans, J. C., Luguri, J. B., Clark, C. J., Schooler, J. W., Baumeister, R. F., \& Vohs, K. D. (2014). Free will and punishment: A mechanistic view of human nature reduces retribution. Psychological Science, 25, 1563-1570.

Smith, D. L. 2011. Less than human: Why we demean, enslave, and exterminate others. New York: St. Martin's Press.

Smithdeal, M. (2016). Belief in free will as an adaptive, ungrounded belief. Philosophical Psychology, 28, 1241-1252.

Stillman, T. F., \& Baumeister, R. F. (2010). Guilty, free, and wise: Determinism and psychopathy diminish learning from negative emotions. Journal of Experimental Social Psychology, 46, 951-960.

Viney, W., Waldman, D., \& Barchilon, J. (1982). Attitudes toward punishment in relation to beliefs in free will and determinism. Human Relations, 35, 939-950.

Vohs, K. D., \& Schooler, J. (2008). The value of believing in free will: Encouraging a belief in determinism increases cheating. Psychological Science, 19, 49-54.

Vonasch, A. J., Clark, C. J., Lau, S., Vohs, K. D., \& Baumeister, R. F. (2017). Ordinary people associate addiction with loss of free will. Addictive Behaviors Reports, 5, 56-66.

Wegner, D. M. (2004). Precis of the illusion of conscious will. Behavioral and Brain Sciences, $27,649-659$. 
Wright, A. G. C., Stepp, S. D., Scott, L. N., Hallquist, M. N., Beeney, J. E., Lazarus, S. A., \& Pilkonis, P. A. (2017). The effect of pathological narcissism on interpersonal and affective processes in social interactions. Journal of Abnormal Psychology, 126, 898-910.

Zajenkowski, M., Witowska, J., Maciantowicz, O., \& Malesza, M. (2016). Vulnerable past, grandiose present: The relationship between vulnerable and grandiose narcissism, time perspective and personality. Personality and Individual Differences, 98, 102-106.

Zhang, Y., \& Tu, Y. (2011). The impact of associative strength on performance in goal pursuit. Journal of Experimental Social Psychology, 47, 1-8.

Zhao, X., Liu, L., Zhang, X-x., Shi, J-x., \& Huang, Z-w. (2014). The effect of belief in free will on prejudice. PLOS ONE, 9, 1-15. 


\section{APPENDIX A: FREE WILL INVENTORY}

Instructions: Please indicate how much you agree with each of the following statements.

\begin{tabular}{ccccccc}
$\begin{array}{c}\text { Strongly } \\
\text { Disagree }\end{array}$ & Disagree & $\begin{array}{c}\text { Somewhat } \\
\text { Disagree }\end{array}$ & $\begin{array}{c}\text { Neither } \\
\text { Agree nor } \\
\text { Disagree }\end{array}$ & $\begin{array}{c}\text { Somewhat } \\
\text { Agree }\end{array}$ & Agree & $\begin{array}{c}\text { Strongly } \\
\text { Agree }\end{array}$ \\
\hline 1 & 2 & 3 & 4 & 5 & 6 & 7 \\
\hline
\end{tabular}

FWI Part 1:

The Free Will Subscale (FW):

1. People always have the ability to do otherwise.

2. People always have free will.

3. How people's lives unfold is completely up to them.

4. People ultimately have complete control over their decisions and their actions.

5. People have free will even when their choices are completely limited by circumstances.

The Determinism Subscale (DE):

1. Everything that has ever happened had to happen precisely as it did, given what happened before.

2. Every event that has ever occurred, including human decisions and actions, was completely determined by prior events.

3. People's choices and actions must happen precisely the way they do because of the laws of nature and the way things were in the distant past.

4. A supercomputer that could know everything about the way the universe is now could know everything about the way the universe will be in the future.

5. Given the way things were at the Big Bang, there is only one way for everything to happen in the universe after that. 
The Dualism/Anti-Reductionism Scale (DU):

1. The fact that we have souls that are distinct from our material bodies is what makes humans unique.

2. Each person has a non-physical essence that makes that person unique.

3. The human mind cannot simply be reduced to the brain.

4. The human mind is more than just a complicated biological machine.

5. Human action can only be understood in terms of our souls and minds and not just in terms of our brains.

\section{FWI Part 2:}

1. Free will is the ability to make different choices even if everything leading up to one's choice (e.g., the past, the situation, and their desires, beliefs, etc.) were exactly the same.

2. Free will is the ability to make a choice based on one's beliefs and desires such that, if one had different beliefs or desires, one's choice would have been different as well.

3. People could have free will even if scientists discovered all of the laws that govern all human behavior.

4. To have free will means that a person's decisions and actions could not be perfectly predicted by someone else no matter how much information they had.

5. If it turned out that people lacked non-physical (or immaterial) souls, then they would lack free will.

6. To have free will is to be able to cause things to happen in the world without at the same time being caused to make those things happen.

7. People have free will as long as they are able to do what they want without being coerced or constrained by other people. 
8. To be responsible for our present decisions and actions we must also be responsible for all of our prior decisions and actions that led up to the present moment.

9. People deserve to be blamed and punished for bad actions only if they acted of their own free will.

10. People who harm others deserve to be punished even if punishing them will not produce any positive benefits to either the offender or society-e.g., rehabilitation, deterring other would-be offenders, etc.

11. People who perform harmful actions ought to be rehabilitated so they no longer pose a threat to society.

12. People who perform harmful actions ought to be punished so that other potential offenders are deterred from committing similar harmful actions.

13. People could be morally responsible even if scientists discovered all of the laws that govern human behavior.

14. If it turned out that people lacked non-physical (or immaterial) souls, then they would lack moral responsibility. 


\section{APPENDIX B: INTERPERSONAL OBJECTIFICATION SCALE VALIDATION}

Instructions: Please indicate how much you agree with each of the following statements.

\begin{tabular}{ccccccc}
$\begin{array}{c}\text { Strongly } \\
\text { Disagree }\end{array}$ & Disagree & $\begin{array}{c}\text { Somewhat } \\
\text { Disagree }\end{array}$ & $\begin{array}{c}\text { Neither } \\
\text { Agree nor } \\
\text { Disagree }\end{array}$ & $\begin{array}{c}\text { Somewhat } \\
\text { Agree }\end{array}$ & Agree & $\begin{array}{c}\text { Strongly } \\
\text { Agree }\end{array}$ \\
\hline 1 & 2 & 3 & 4 & 5 & 6 & 7 \\
\hline
\end{tabular}

1. In life, we all basically use other people as a means to our own ends.

2. Forcing someone to have sex against his or her will is immoral. (R)

3. Telling someone that you love them, even if you don't, in order to get them to have sexual relations with you is immoral. (R)

4. It is important to me to be aware of and respect any sexual dislikes or limits that my partner expresses. (R)

5. If someone doesn't do as I request, I look to find someone else who will.

6. Pretending to have no money to get another person to pay for your meal is immoral. (R)

7. It's not a big deal when a man grabs a woman's butt at a party or a bar.

8. If you are not deriving sufficient sexual gratification in your relationship with a committed partner, it is okay to fool around a little so long as it doesn't hurt your committed partner.

9. In close relationships, there should be a balance of power where each person has an equal say in most decisions. (R)

10. When first meeting someone who interests me, I take note of particular body parts such as their legs, eyes, chest, etc.

11. I don't give others' feelings much thought. 
12. If I am in a sexual relationship with someone, it is important that I ask her/him about personal sexual likes and dislikes. (R)

13. People basically fill different places in your life such as best friends, romantic partner, or drinking buddy. In general, it is okay to replace them if you find others who can do a better job.

14. When I have lost a friend, I find it easy to replace that friend with a new one.

15. I believe that, when you are in love with someone, there is something irreplaceable about them-even though others might be just as attractive and as nice, you don't feel like they could replace your loved one. $(\mathrm{R})$

16. In a sexual situation, if someone says "no," I think it's okay to keep pushing to see if they really mean it.

17. Coming on aggressively to get an unwilling person to have sex with you is okay.

18. When I am involved or getting involved with someone, I want to understand on an intimate level who they really are as a person. (R)

19. If a person is not getting their sexual needs met in their primary relationship, it is okay to get them met elsewhere.

20. It is morally wrong for a business owner to fire one employee and hire another employee because they could be paid less. (R)

21. Taking credit for work that a coworker actually did to get a promotion is wrong. (R)

22. If I am in a serious romantic relationship, I feel as though my partner is in a sense my property until that relationship ends.

23. The practice of purchasing a bride, still observed in many countries around the world, is immoral. (R) 
24. In a recent drama, a man says to a woman: "If you aren't going to meet my needs, I'll find someone who can." I believe that this man's attitude is an acceptable one.

25. I often try to pay attention to the feelings of those around me. (R)

26. I sometimes try to understand my friends better by imagining how things look from their perspective. (R)

27. The primary reason to make friends is because friends will likely be useful to you.

28. In a sexual encounter, it is important for both parties to respect the desires, as well as the personal limits, of the other. (R)

29. Using other people to get ahead is immoral. (R) 


\section{APPENDIX C: INTERPERSONAL OBJECTIFICATION SCALE}

Instructions: Please indicate how much you agree with each of the following statements.

\begin{tabular}{ccccccc}
$\begin{array}{c}\text { Strongly } \\
\text { Disagree }\end{array}$ & Disagree & $\begin{array}{c}\text { Somewhat } \\
\text { Disagree }\end{array}$ & $\begin{array}{c}\text { Neither } \\
\text { Agree nor } \\
\text { Disagree }\end{array}$ & $\begin{array}{c}\text { Somewhat } \\
\text { Agree }\end{array}$ & Agree & $\begin{array}{c}\text { Strongly } \\
\text { Agree }\end{array}$ \\
\hline 1 & 2 & 3 & 4 & 5 & 6 & 7 \\
\hline
\end{tabular}

\section{Perspective-Taking}

1. Pretending to have no money to get another person to pay for your meal is immoral. (R)

2. In close relationships, there should be a balance of power where each person has an equal say in most decisions. (R)

3. If I am in a sexual relationship with someone, it is important that I ask them about personal sexual likes and dislike. (R)

4. When I am involved or getting involved with someone, I want to understand on an intimate level who they are as a person. (R)

5. The practice of purchasing a bride, still observed in many countries around the world, is immoral. (R)

6. I often try to pay attention to the feelings of those around me. (R)

7. I sometimes try to understand my friends better by imagining how things look from their perspective. (R)

\section{Sexual Gratification}

1. It's not a big deal when a man grabs a woman's butt at a party or a bar.

2. If you are not deriving sexual gratification in your relationship with a committed partner, it is okay to fool around a little so long as it doesn't hurt your committed partner. 
3. In a sexual situation, if someone says "no," I think it's okay to keep pushing to see if they really mean it.

4. Coming on aggressively to get an unwilling person to have sex with you is okay.

5. If a person is not getting their sexual needs met in their primary relationship, it is okay to get them met elsewhere.

Instrumentality

1. In life, we all basically use other people as a means to our own ends.

2. If someone doesn't do as I request, I look to find someone else who will.

3. People basically fill different places in your life such as best friends, a romantic partners, or a drinking buddy. In general, it is okay to replace them if you find others who can do a better job. 


\section{APPENDIX D: SHORT DARK TRIAD}

Instructions: Please indicate how much you agree with each of the following statements.

Disagree

Neither Agree

Agree

Strongly

Disagree

nor Disagree

Agree

Strongly

Machiavellianism

1. It's not wise to tell your secrets.

2. I like to use clever manipulation to get my way.

3. Whatever it takes, you must get the important people on your side.

4. Avoid direct conflict with others because they may be useful in the future.

5. It's wise to keep track of information that you can use against people later.

6. You should wait for the right time to get back at people.

7. There are things you should hide from other people to preserve your reputation.

8. Make sure your plans benefit yourself, not others.

9. Most people can be manipulated.

Narcissism

1. People see me as a natural leader.

2. I hate being the center of attention. (R)

3. Many group activities tend to be dull without me.

4. I know that I am special because everyone keeps telling me so.

5. I like to get acquainted with important people.

6. I feel embarrassed if someone compliments me. (R)

7. I have been compared to famous people.

8. I am an average person. (R) 
9. I insist on getting the respect I deserve.

\section{Psychopathy}

1. I like to get revenge on authorities.

2. I avoid dangerous situations. (R)

3. Payback needs to be quick and nasty.

4. People often say I'm out of control.

5. It's true that I can be mean to others.

6. People who mess with me always regret it.

7. I have never gotten into trouble with the law. (R)

8. I enjoy having sex with people I hardly know.

9. I'll say anything to get what I want. 


\section{APPENDIX E: OBJECTIFICATION SCALE}

Instructions: Consider a previous or current work relationship. Please indicate how much you agree with each of the following statements based on your perception of the relationship.

\begin{tabular}{ccccccc}
$\begin{array}{c}\text { Strongly } \\
\text { Disagree }\end{array}$ & Disagree & $\begin{array}{c}\text { Somewhat } \\
\text { Disagree }\end{array}$ & $\begin{array}{c}\text { Neither } \\
\text { Agree nor } \\
\text { Disagree }\end{array}$ & $\begin{array}{c}\text { Somewhat } \\
\text { Agree }\end{array}$ & Agree & $\begin{array}{c}\text { Strongly } \\
\text { Agree }\end{array}$ \\
\hline 1 & 2 & 3 & 4 & 5 & 6 & 7 \\
\hline
\end{tabular}

1. I think more about what this person can do for me than what I can do for him $/ \mathrm{her}$.

2. I tend to contact this person only when I need something from him/her.

3. I am interested in this person's feelings because I want to be close with him/her. (R)

4. I try to motivate him/her to do things that will help me succeed.

5. The relationship is important to me because it helps me accomplish my goals.

6. This person is very useful to me.

7. My relationship with this person is based on how much I enjoy our relationship, rather than how productive our relationship is. $(\mathrm{R})$

8. If the nature of my job (or his/her job) changed and this person wasn't helpful anymore, the relationship probably wouldn't continue.

9. Someone else with the same skill set could become equally important to me.

10. I really like this person a lot even though $\mathrm{s} / \mathrm{he}$ is not all that useful to me. (R)

(R) reverse-scored item 


\section{APPENDIX F: INFORMED CONSENT}

\section{SONA System Informed Consent}

You are being asked to participate in a research study conducted by Rachel Boros, Graduate Student in the Clinical-Counseling Psychology program at Illinois State University. The purpose of this research is to examine potential implications of certain widely promoted beliefs in American society; specifically, if and how these beliefs may affect individual's moral behavior and psychological well-being.

Participants must be 18 years and older to take part in the study. If you choose to participate, the survey will take approximately 20 minutes to complete. Your participation in this study is voluntary and you may withdraw from the study at any time without penalty. You are ineligible to participate if you are currently within the European Economic Area.

Your participation will be compensated through 0.5 SONA credits that may be used as extra credit in your psychology courses. While you might not be directly benefiting from this study, the study has significant implications for very important societal issues regarding factors affecting people's moral behavior and psychological well-being.

The findings from this study may be presented in conferences, meetings, and publications. We do not anticipate any risks beyond those that would occur in everyday life. If you have any questions regarding the present research study or wish to withdraw from the study, contact Dr. Raymond Bergner at rmbergn@ilstu.edu. If you have any questions about your rights as a participant, or if you feel you have been placed at risk, contact the Illinois State University Research Ethics \& Compliance Office at (309) 438-5527 or IRB@ilstu.edu.

Please indicate below if you are willing to be in the study. By selecting the "Yes" option, you are indicating that you voluntarily agree to participate in this study, that the study has been 
explained to you, and that you have been given the time to read the document and that your questions have been satisfactorily answered.

Please be sure to save this consent as a PDF or print a copy for your records.

\section{Mass Email Informed Consent}

You are being asked to participate in a research study conducted by Rachel Boros, Graduate Student in the Clinical-Counseling Psychology program at Illinois State University. The purpose of this research is to examine potential implications of certain widely promoted beliefs in American society; specifically, if and how these beliefs may affect individual's moral behavior and psychological well-being.

Participants must be 18 years and older to take part in the study. If you choose to participate, the survey will take approximately 20 minutes to complete. Your participation in this study is voluntary and you may withdraw from the study at any time without penalty. You are ineligible to participate if you are currently within the European Economic Area.

To compensate you for your time spent on this study, you can be entered into a raffle for a \$20 Amazon gift card. To be eligible, you will be taken to a separate page at the end of the survey to enter your contact information. This information will be kept entirely separate from the survey and your responses. Once the compensation is distributed, we will delete your contact information. The IRS may consider these payments to be taxable compensation. Recipients of a research participant incentive payment may want to consult with their personal tax advisor for advice regarding the participant's situation. Any participant also has the opportunity to participate in the study without accepting the research incentive payment.

The findings from this study may be presented in conferences, meetings, and publications. We do not anticipate any risks beyond those that would occur in everyday life. If 
you have any questions regarding the present research study or wish to withdraw from the study, contact Dr. Raymond Bergner at rmbergn@ilstu.edu. If you have any questions about your rights as a participant, or if you feel you have been placed at risk, contact the Illinois State University Research Ethics \& Compliance Office at (309) 438-5527 or IRB@ilstu.edu.

Please indicate below if you are willing to be in the study. By selecting the "Yes" option, you are indicating that you voluntarily agree to participate in this study, that the study has been explained to you, and that you have been given the time to read the document and that your questions have been satisfactorily answered.

Please be sure to save this consent as a PDF or print a copy for your records. 


\section{APPENDIX G: DEBRIEFING STATEMENT \\ Debriefing Statement}

Thank you for your participation. The responses you provided are completely anonymous and will remain confidential.

The purpose of this study was to investigate potential implications of believing in free will; more specifically, if and how a belief in the alternative, determinism, may affect individuals' moral behavior and psychological well-being. Your responses to this survey may provide insight into the effects of widely accepted beliefs, but possibly personally and socially damaging belief systems in American society.

I hope and believe that this questionnaire did not cause any distress. However, if you are experiencing personal distress, you can participate in free counseling services at Illinois State University Student Counseling Services, located on the third floor of the Student Services Building. Call (309)438-3655 or schedule an appointment online at https://counseling.illinoisstate.edu/.

This research is supervised by Raymond Bergner, PhD, Professor in Psychology. You can reach him at (309)438-8190, via email at rmbergn@ilstu.edu, or at his office in room 440 of DeGarmo Hall.

A majority of research conducted in psychology is dependent on voluntary participation by individuals like yourself. We are very appreciative of your help. Thank you again for participating!

Sincerely, Rachel Boros 
Master of Science Candidate

Clinical-Counseling Psychology Program

Department of Psychology

Illinois State University 